\title{
Phyllosphere-inhabiting endophytic bacteria feature a stationary phase-like lifestyle
}

\author{
André C. Velásquez ${ }^{1^{*}}$, José C. Huguet-Tapia ${ }^{2}$, and Sheng Yang $\mathrm{He}^{1,3^{*}}$ \\ ${ }^{1}$ Howard Hughes Medical Institute, Duke University, Durham, NC 27708, USA; ${ }^{2}$ Department of \\ Plant Pathology, University of Florida, Gainesville, FL 32611, USA; and ${ }^{3}$ Department of Biology, \\ Duke University, Durham, NC 27708, USA.
}

*Correspondence: andre.velasquez@duke.edu, shengyang.he@duke.edu

\section{ABSTRACT}

Plants are in constant association with a variety of microbes, and although much is known about how symbiotic and pathogenic microbes interact with plants, less is known about the population dynamics, adaptive traits, and transcriptional features of endophytic commensal microbes that live inside leaves. In this study, we evaluated the long-term population and transcriptional dynamics of two bacterial microbiota endophytes and compared them to those of a commensal-simulating nonpathogenic mutant of the bacterial pathogen Pseudomonas syringae. We found that population densities of all three endophytic phyllosphere bacteria remained static over a long period of time, which was caused by a continual equilibrium between bacterial multiplication and death, as evidenced by treatment of plants with antibiotics that only targeted dividing bacteria or by in planta visualization of bacteria carrying a fluorescent division reporter. Population stasis could not be explained by a lack of resources, as Arabidopsis leaves could support population densities up to 100 times higher than the normal microbiota populations, nor was population stasis reversed by significantly quenching PAMP-triggered immunity. Long-term temporal in planta transcriptomic analysis of these three bacterial endophytes revealed up-regulation of protein translation, the generation of energy, and the response to stress, and interestingly, for the microbiota strains, the longer the bacteria remained inside plants, the greater the up-regulation of some of these processes. Further transcriptomic analysis of in planta populations of commensal-simulating Pseudomonas syringae revealed a remarkable resemblance to those of in vitro bacteria in stationary phase, a metabolically active physiological state in which the production of secondary metabolites and stress responses are induced. This study provides novel insight into how endophytic bacteria survive and thrive inside plant leaves, and reshapes our current understanding of what it means to be part of the endophytic microbiota in the phyllosphere.

\section{KEYWORDS}


Population stasis, Plant microbiota, Bacterial transcriptome, Stationary phase, Pseudomonas syringae, Achromobacter, Pandoraea.

\section{INTRODUCTION}

Plants are exposed to a multitude of microbes during their life cycles. Interactions of plants with microbes may range from causing no observable effect (commensal interactions) to forming intricate symbiotic relationships with specialized organs for nutrient acquisition (Hassani et al. 2018). Of the myriad extant microbes, only very few are capable of causing disease in a particular host: probably only tens of microbes will cause disease in a particular host, while most biotrophic pathogens have a very narrow host range (Morris and Moury 2019). Due to their great impact on crop production and natural ecosystems, symbiotic and pathogenic microbes have received great attention in the past. By contrast, insight into the lives of the vast number of commensal microbes is lagging behind.

Of commensal bacteria that live on the phyllosphere (above-ground parts) of plants, most live on the surface as epiphytes, probably because the plant interior (specifically the apoplast) exerts a strong selection pressure on the type of microbes that can grow and multiply. Not only are bacterial epiphytes more than 100 times more abundant than endophytes, but also the microbiota composition is different (Chen et al. 2020b). Commensal bacterial endophyte population numbers are low; in Arabidopsis (Arabidopsis thaliana) the number of culturable endophytes appears to be fewer than $10^{4} \mathrm{CFU} \mathrm{cm}{ }^{-2}$ (Chen et al. 2020b, Xin et al. 2016). By contrast, the population density of pathogenic endophytic bacteria, such as Pseudomonas syringae, can increase to almost the carrying capacity of the plant (Xin et al. 2018), unless the plant surveillance systems mounts effector-triggered immunity (ETI) upon effector recognition (Deslandes et al. 2002, Macho et al. 2012). Interestingly, in the absence of virulence-promoting effector proteins and toxins, nonpathogenic mutants of $P$. syringae, such as the $\triangle$ hrcC $\triangle C F A$ mutant (defective in the type III secretion system and coronatine production), are unable to multiply to high levels, resembling commensal bacteria that normally reside in the leaf apoplast (Worley et al. 2013).

The transcriptomes of phyllosphere-inhabiting pathogenic bacteria have been analyzed in the past few years to obtain clues into the processes that influence plant colonization. A microarray-based approach revealed differences in gene expression between epiphytic and apoplastic pathogenic Pseudomonas syringae, from which it was inferred that bacteria residing in the plant apoplast experience a more taxing osmotic stress than those that live on the surface of the leaves (at 48-72 hours post- inoculation; Yu et al. 2013). A more recent transcriptomics study of the early responses of Pseudomonas syringae (6 hours after inoculation) showed a strong 
correlation between bacterial genes responsive to the plant immune system and future bacterial densities (Nobori et al. 2018). However, to date, the nature of the long-term bacterial population homeostasis and associated transcriptomic dynamics of non-pathogenic endophytic commensal phyllosphere bacteria has not been evaluated, leaving a significant gap in the understanding of population and molecular features that are important for long-term adaptation and survival of commensal microbiota to the apoplastic environment of the phyllosphere.

There are several non-mutually exclusive plausible explanations for the inability of a microbe to survive and/or multiply inside the plant apoplast: (a) plant surface barriers do not allow for microbe invasion into plants (Ellinger et al. 2013, Lee et al. 2019). (b) a nutritional deficiency in the plant's apoplast that the microbe cannot overcome (Bezrutczyk et al. 2018). (c) the concentration of free water in the apoplast is too low for the microbe to multiply (Wright and Beattie 2004). (d) the microbe cannot counteract plant immune defenses (Cunnac et al. 2011, Stoitsova et al. 2008, Fan et al. 2011). (e) host inducers of microbial virulence and/or survival mechanisms are not present in plants, or are actively sequestered (Anderson et al. 2014, Wang et al. 2020); and (f) for biotrophic microbes that cause plant cell death, niche destruction does not allow the microbe to grow (Balint-Kurti 2019).

We conducted a detailed study to understand the population dynamics of two common bacterial commensal endophytes as well as a commensal-simulating mutant of $P$. syringae pv. tomato DC3000 in Arabidopsis leaves. We then used multi-time-point transcriptomic analysis to infer the biological processes important for a long-term commensal lifestyle in the leaf apoplast. Our results point to a previously unrecognized stationary phase-like lifestyle for phyllosphereinhabiting endophytic bacteria. This population stasis was caused by equilibrium in the rates of multiplication and death of phyllosphere-inhabiting endophytes. This finding has significant implications in understanding commensal plant-endophytic microbiota interactions and in guiding the application of endophytic commensal microbiota in agricultural and natural ecosystem settings.

\section{RESULTS}

\section{Non-pathogenic phyllosphere bacterial population densities are static}

A naïve assumption for the outcome after phyllosphere bacterial strains lacking virulence mechanisms are inoculated into plant leaves would be that the plant immune system would eventually clear out those invading microbes by producing antibacterial compounds. We tested this possibility by inoculating a disarmed (no longer pathogenic) strain, Pseudomonas syringae pv. tomato (Pst) DC3000 $\Delta h r c C \triangle C F A$, into Arabidopsis leaves and evaluating the population densities over the course of four weeks. Pst $\triangle h r c C \triangle C F A$ has been rendered essentially non-pathogenic by 
eliminating its two main virulence determinants: the ability to form a type III secretion system ( $h r c C)$ and the production of the phytotoxin coronatine (CFA) (Worley et al. 2013). As such, Pst $\triangle h r c C \triangle C F A$ is unable to cause disease. As can be observed in Figure $1 \mathrm{~A}$, the bacterial population densities remained unchanged over the course of 4 weeks, suggesting that for this particular plant-microbe interaction, antimicrobial compounds are not significantly altering the bacterial population densities.

Phyllosphere-inhabiting bacteria also include pathogenic strains that trigger ETI in incompatible plants, and are therefore unable to cause disease. Bu-22 is an Arabidopsis accession in which the Pst virulence-promoting effector AvrPto is recognized in order to mount ETI (Velásquez et al. 2017). Bu-22 plants carry a single locus responsible for AvrPto recognition that we named RPS7 (Resistance to Pseudomonas syringae $\underline{7}$ ). When we inoculated Pst DC3000 into the Arabidopsis accession Bu-22, there was only a slight increase in growth very early in the interaction (before 4 days post-inoculation [dpi]), after which the bacterial population densities remained static (Figure 1B). Taken together, these results suggest that for phyllosphere microbes that trigger ETI and for non-pathogenic bacteria, the plant immune system maintains the microbial population numbers without fully eliminating bacteria from the plant apoplast.

We wanted to know if the population stasis phenomenon was widespread and if it also applied to normal non-pathogenic leaf microbiota strains. We inoculated into Arabidopsis plants three bacterial strains that had been previously isolated from Arabidopsis leaves: the $\beta$ Proteobacteria Achromobacter xylosoxidans Col-0-50 and Pandoraea sp. Col-0-28 (Tao et al. 2020), and the gram-positive Actinobacteria Rhodococcus sp. 964 (Bodenhausen et al. 2014) into Arabidopsis plants. These microbiota strains were chosen because they did not cause any disease-like symptoms when inoculated into leaves at very high population densities (Bodenhausen et al. 2014, Tao et al. 2020). After three weeks, population densities did not change for either Proteobacteria strain (Figure $1 \mathrm{C}$ and Figure S1A), while there was a very small initial increase in growth for Rhodococcus (Supplementary Figure $\mathrm{S} 1 \mathrm{~A}$ ). We also tested additional $R$ gene-effector pair interactions that caused ETI in Arabidopsis. For three additional interactionsrecognition of AvrRpt2, AvrRps4, and AvrPphB by RSP2, RPS4 and RPS5, respectivelypopulation stasis of Pst was observed (other than the small initial population density increase; Supplementary Figure S1B), similar to the effect observed during the interaction between RPS7 and AvrPto. The only bacterial strain for which we did not observe population stasis was Pseudomonas fluorescens $0-1$, a bacterium originally isolated from soil. For this strain, the population density numbers decreased over time, but never reached zero, not even after almost 3 weeks after inoculation (Figure 1D). Overall, these results suggest that population stasis occurs for 
most phyllosphere non-pathogenic bacteria (8 out of 9 strains) once they are inside plants, and that plant defenses, including ETI, keep bacterial population densities constant.

\section{Bacterial population stasis occurs irrespective of bacterial population density or a functional PTI system}

It is possible that the population stasis phenomenon is only observed at a specific population density, one at which the carrying capacity of the system has been reached. To test this possibility, we inoculated Pst $\triangle$ hrcC $\triangle C F A$ into Arabidopsis leaves at four different initial population densities (covering 3 orders of magnitude) and evaluated the resulting population densities over 2 weeks. Irrespective of the bacterial inoculum, the population density numbers did not change over time (Figure 2A). At the highest initial population density $\left(5 \times 10^{8} \mathrm{CFU} \mathrm{mL}{ }^{-1}\right)$, inoculated leaves did not continue to grow over the course of the experiment, in accordance with the well-known dichotomy between growth and defense, in which only one process at a time is prioritized for resources by plants (Supplementary Figure S2A, Huot et al. 2014). Not only that, an earlier onset-senescence phenotype was also observed for leaves infiltrated at the highest inoculum. This result suggests that the growth-defense tradeoffs might not be important for plant-commensal interactions at the natural endophyte population density that exists in nature. Additionally, the lack of differences in the overall population stasis phenotype at different initial population densities suggests that a lack of resources cannot explain why phyllosphere non-pathogenic bacteria are unable to multiply to achieve high population densities, as populations of up to $10^{6} \mathrm{CFU} \mathrm{\textrm {cm } ^ { - 2 }}$ were able to be maintained inside leaves.

Suppression of PTI alone does not seem to confer a dramatic increase in bacterial population density in planta (less than a 10-fold increase, Xin et al. 2016), at least not in the few days after inoculation when the samples were collected. We reasoned, however, that perhaps evaluating population densities over the course of weeks rather than days would show a small but continuous increase in bacterial population densities in PTI-compromised mutant plants. However, this was not the case when we inoculated a PTI mutant deficient in three PTI co-receptors (bak1 bkk1 cerk1, involved in the recognition of multiple microbe-associated molecular patterns [MAMPs]; Xin et al. 2016) with multiple bacterial strains and compared the population densities to that of wild-type plants (Figure $2 \mathrm{~B}$ and Supplementary Figure $\mathrm{S} 2 \mathrm{~B}$ ). Even though population densities of Pst $\triangle$ hrcC $\triangle C F A$ and Rhodococcus were larger in the PTI triple mutant than in the wild type, these populations did not continue to increase over time and remained static after an initial growth (Figure 2B and Supplementary Figure S2B). Additionally, for $P$. fluorescens, there was a decrease in population density over time, as had been observed for wild-type plants (Figure 1D), even though population density initially increased in the PTI triple mutant (Figure 2B). The plant 
immune defense is composed of many layers, and we can infer from these results that the failure of non-pathogenic microbes to continuously increase their population densities is not exclusively determined by PTI.

\section{Reversibility of bacterial stasis after PTI priming}

Virulent bacteria may be rendered non-pathogenic in plants in which PTI priming has occurred, such as when a PTI inducer is added hours before bacterial inoculation, allowing for plant defenses to be primed and in high alert before pathogen arrival (Zipfel et al. 2004). We wanted to test whether PTI-mediated defenses render bacteria in a physiological state that could easily be reversed if the conditions became favorable. To do this, we recovered bacteria from plants pretreated or not with an epitope of the PTI inducer flagellin, flg22. Before recovery, mock-treated virulent Pst DC3000 bacteria were able to multiply to the plant's carrying capacity, while bacteria in PTI-primed plants did not increase in population density (Supplementary Figure S2C).

We used the recovered bacteria to inoculate naïve plants and found that there were no differences in population densities from bacteria recovered from PTI-primed or mock-treated plants (Figure 2C). The only difference observed was the higher earlier population densities of bacteria recovered from plants (at $1 \mathrm{dpi}$ ), compared to those that used an in vitro grown inoculum. This difference is likely reflective of the very low expression of genes involved in virulence mechanisms in bacteria grown in rich media (Nobori et al. 2018). The inability of bacteria to grow in PTI-primed plant tissue disappeared over time, further supporting the conclusion that this induced, static bacterial physiological state is reversible (Supplementary Figure S2D).

\section{Equilibrium between bacterial multiplication and death explains static population densities}

Population density stability after the colonization of non-pathogenic phyllosphere microbes might be reflective of bacterial cells that completely cease to divide, or of an equilibrium between the rates of death and multiplication of such cells. To try to differentiate between these two possibilities, we used $\beta$-lactam antibiotics, which only target cells that are actively dividing (Spoering and Lewis 2001). We confirmed the in vitro cell-multiplication inhibitory effect of the bacterial cell-wall biosynthesis-targeting $\beta$-lactam antibiotic carbenicillin on Pst $\triangle h r c C \Delta C F A$ (Figure 3A). As expected, cells in the logarithmic phase were killed by carbenicillin as soon as they tried to divide (Figure 3A). However, when the cells had reached stationary phase, adding a $\beta$-lactam antibiotic had no effect on them. The reduction in population density for both the mock and carbenicillin treatments for stationary cells at later time points was likely caused by nutrient depletion in the medium (Navarro Llorens et al. 2010). 
To know if we can use carbenicillin to kill dividing bacteria inside plants, we inoculated Arabidopsis leaves with Pst DC3000, followed with infiltration of carbenicillin 1 and 2 days after inoculation. Pst DC3000 is virulent in Arabidopsis Col-0 plants and is expected to rapidly multiply once inside the apoplast. A greater than 100,000-fold increase in population density was observed between days 1 and 3 for the $\mathrm{H}_{2} \mathrm{O}$ control, which corresponds on average to approximately eleven cell divisions per inoculated bacterial cell (Supplementary Figure S3A). By contrast, in leaves infiltrated with carbenicillin, bacterial populations numbers were even lower at day 3 than they were before treatment (at day 1 ). More than $99.99 \%$ of cells attempted to divide and were killed by the $\beta$ lactam antibiotic. We can infer from this result that carbenicillin is very effective in killing dividing Pst DC3000 cells within plants.

We used carbenicillin to evaluate whether non-pathogenic Pst $\triangle h r c C \triangle C F A$ was able to multiply inside plants, or if cells had been rendered truly in stasis. Population densities of Pst $\triangle h r c C \triangle C F A$ treated with the antibiotic were reduced after 5 consecutive days of treatment (at 6 days post-infiltration) when compared to the mock $\mathrm{H}_{2} \mathrm{O}$ control (Figure 3B). Approximately $75 \%$ of all bacterial cells attempted to divide over 5 days and were killed by the antibiotic. When using conditions that favored even more bacterial multiplication (by increasing the relative humidity to over $99 \%$ ), more than $98 \%$ of dividing bacterial cells were killed (Supplementary Figure S3B).

A similar antibiotic treatment experiment using microbiota strains Pandoraea and Rhodococcus yielded similar results. Five days after $\beta$-lactam antibiotic treatment, reduction in bacterial population densities was approximately $80 \%$ for Pandoraea (this experiment used a different $\beta$-lactam antibiotic, cefotaxime, as Pandoraea is resistant to carbenicillin; Figure 3B), while for Rhodococcus this reduction was almost 90\% (Supplementary Figure S3C). Overall, these results suggest that bacterial endophytes are actively multiplying and dying inside plants, and that both rates are equivalent. This equilibrium would cause microbiota population densities to effectively remain static over time.

\section{Visualization of population stasis of commensal bacteria}

In order to differentiate multiplying from static bacteria inside plants, we generated a bacterial system whereby fluorescence signal was used as a reporter of bacterial stasis. We integrated into the Pst genome a reporter that expressed two fluorescent proteins: mCerluean3 (Markwardt et al. 2011), expressed constitutively, and mCitrine (Griesbeck et al. 2001), expressed under the control of an inducible tetracycline promoter (Bertram and Hillen 2008; Figure 4A). If we grow the inoculum under the presence of a tetracycline analogue (anhydrotetracycline), bacteria would be doubly fluorescent for mCerulean3 and $\mathrm{mCitrine.} \mathrm{When} \mathrm{inoculating} \mathrm{such} \mathrm{bacteria} \mathrm{into} \mathrm{plants,} \mathrm{the} \mathrm{mCitrine}$ signal would become diluted if the bacteria divide, as anhydrotetracycline would no longer be 
available to induce fluorescent protein expression. If multiple cell divisions occur, the mCitrine signal would become diluted past the point of detection, and the cells would only be detected by the mCerulean3 signal (Figure 4A). Therefore, static cells that do not multiply would be fluorescent for both fluorescent proteins, while newly divided cells would not express mCitrine and after several divisions would be fluorescent only for mCerulean3.

We first tested the inducibility of our reporter system in vitro. Indeed, Pst $\triangle$ hrcC $\triangle C F A$ cells carrying the reporter were detected by only mCerulen3 signal in the absence of anhydrotetracycline, and by both mCerulean3 and mCitrine signals when anhydrotetracycline was added to the in vitro medium (Figure 4B). Note that the inducible mCitrine signal was overall lower, on average, than that of the constitutive mCerulean3 fluorescent protein.

We then tested the function of our reporter in planta. Virulent Pst DC3000 carrying the reporter and originally grown in vitro in the presence of the anhydrotetracycline inducer was inoculated into Arabidopsis Col-0 plants at a low density that was well below the detection level of our confocal microscopy set-up (day 0; Figure 4C). After 2 days of growth in planta, only mCerulean3 signal became detectable because bacteria multiplied to population densities well past the detection minimum, while mCitrine signal never became detectable, as mCitrine expression was absent inside plants, and the original $\mathrm{mCitrine}$ signal from the inoculum was diluted. At this point of the infection with Pst DC3000, symptoms were starting to appear on the leaves and the entirety of multiple plant cells had been colonized; the leaf colonization seemed to have reached beyond the apoplastic space. Most likely, these plant cells were dead due to bacterial infection, as at later time points Pst DC3000 causes wilting and necrosis in Arabidopsis (Velásquez et al. 2017). At the leaf surface, it was easier to discern individual bacterial cells and colonization of intercellular spaces by Pst DC3000 (Supplementary Figure S4).

To visualize a phyllosphere-inhabiting microbial endophyte in planta, we inoculated Pst $\triangle h r c C \triangle C F A$ carrying the cell division reporter into Arabidopsis leaves. On day $0, P s t \Delta h r c C \Delta C F A$ had colonized multiple non-continuous regions of the apoplast of plant cells. Both mCerulean3 and mCitrine signals were observed, and their signals overlapped (Figure 4D). These bacteriumcolonized apoplast areas are most likely those in which a liquid environment is present, while those that are not colonized are likely full of pockets of air. It might be that only in pathogenic organisms, the virulence mechanisms would allow access of other areas by using effectors that promote the water soaking of the entire leaf apoplast (Xin et al. 2016; Figure 4C and Supplementary Figure S4).

On day 5, signal from both fluorescent proteins in Pst $\triangle h r c C \Delta C F A$ was still observed (Figure 4D). However, at this point, while some bacterial aggregates had signal from both fluorescent proteins, others had signal only from mCerulean3 (Figures 4D and 4E). This indicates that within a leaf, some of the bacterial cells of the population remain static (at least until 5 days 
post-inoculation), while other cells are multiplying and give rise to new bacterial aggregates (those devoid of mCitrine signal). These results seem to agree with the results obtained with the $\beta$-lactam antibiotic treatment (Figure 3B and Supplementary Figure S3B), in which some of the cells in the population divided while others remained in stasis.

\section{In planta transcriptomics analysis of phyllosphere-inhabiting bacteria}

To try to understand which biological processes are affected during long-term survival of nonpathogenic bacteria inside plants and to gain a glimpse into the causes of population stasis, we performed RNA-Sequencing (RNA-Seq) from Arabidopsis leaves inoculated with bacteria. We focused on two microbiota strains and a disarmed mutant of Pseudomonas: A. xylosoxidans, Pandoraea sp., and Pst $\triangle h r c C \triangle C F A$, respectively. We evaluated the transcriptomes of the inocula before, and at 6,24 , and 168 hours after inoculation of these three bacterial strains into plants. For A. xylosoxidans, we sequenced only the endophytic bacteria by eliminating the surface-inhabiting bacteria with sodium hypochlorite. For Pst $\triangle h r c C \triangle C F A$, we also included in vitro populations of cells that were in logarithmic or stationary phase of growth. The bacterial population densities of the samples used for sequencing are shown in Supplementary Figures S5A, S5B, and S5C. At the

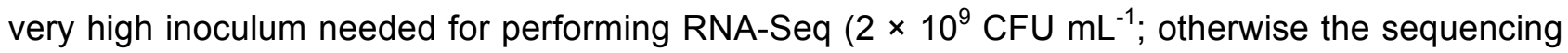
would be overwhelmed by mostly plant RNAs), there was a slight decrease in population densities between 6 and 24 hours. This was most likely caused by a strong initial PTI response due to the overabundance of MAMPs in the inoculum.

For performing RNA-Sequencing, we used a pipeline that we originally described in Nobori et al. (2018), in which bacterial mRNA transcripts are enriched using custom-designed probes during the process of preparing the libraries. To be thorough in calculating differential gene expression (DGE), we used three different methods (for a comparison of the number of differentially expressed genes identified by each of the three methods, see Supplementary Figure S5D): (1) alignment of reads with HISAT2 (Kim et al. 2019), calculation of transcript frequency with StringTie (Kovaka et al. 2019), and DGE with DESeq2 (Love et al. 2014); (2) alignment of reads with HISAT2 and DGE with Cufflinks (Trapnell et al. 2013), and (3) pseudo-alignment of reads with Salmon (Patro et al. 2017), and DGE with DESeq2. Differentially expressed genes present in at least one of the analyses were used for subsequent analysis. A principal component analysis (PCA) indicated that all the samples of every treatment clustered together separately from samples from other treatments (Supplementary Figures S5E and S5F).

In planta gene expression patterns over time of select biological pathways that were enriched in differentially expressed genes in at least one of the different treatment comparisons are presented in Figures $5 \mathrm{~A}$ (for Pst $\triangle h r c C \triangle C F A$; also see Supplementary Figure S6), $5 \mathrm{~B}$ (for $A$. 
xylosoxidans) and 5C (for Pandoraea sp.). A complete list of biological pathways enriched in differentially expressed up or down-regulated genes is shown in Supplementary Table S1. We also performed an analysis for biological pathways enriched in different expression profiles over time to identify sets of genes whose expression increased or decreased once phyllosphere bacteria were inside plants. The expression profiles were calculated using STEM (Ernst and Bar-Joseph 2006) and are shown in Supplementary Table S2. Finally, an analysis to find biological pathways enriched in orthologous genes whose differential expression followed the same pattern of up- or down-regulation in all three strains was performed.

As expected, expression of alginate biosynthesis genes and virulence-promoting mechanisms-including genes for coronatine biosynthesis and type III secretion system structural components and effectors-was up-regulated inside plants for Pst $\triangle$ hrcC $\triangle C F A$ (Nobori et al. 2018). Note that this strain is non-pathogenic, and as such, virulence-promoting mechanisms should not play an essential role in bacterial survival. Primary metabolic pathways for energy and intermediary metabolite generation involved in ATP biosynthesis and hexose catabolism, including the Entner-Doudoroff pathway, Tricarboxylic acid cycle, and the Pentose phosphate pathway (see Supplementary Figure S6), were also up-regulated inside plants. These same primary metabolic pathways were up-regulated in planta when compared to the inoculum for the microbiota strains Achromobacter and Pandoraea (Figure 5D and 5E); however, only in the microbiota endophytes was expression of ATP biosynthesis genes up-regulated the longer the bacteria stayed inside the leaves. The response to oxidative stress was also up-regulated in planta for all three strains, perhaps as an adaptation to the harsher environment encountered by microbes in the apoplast.

Expression of protein translation genes, especially those involved in ribosome biogenesis, was also up-regulated inside plants when compared to the inoculum (Figures 5A, 5B, 5C, and 5D), the only exception being tRNA-coding genes whose expression was in general lower inside plants than in the inoculum irrespective of the time point analyzed (Supplementary Figure S6). Expression of protein translation was higher in both microbiota endophytes after 7 days post-inoculation ( $\left.\mathrm{t}_{168}\right)$ compared to earlier inoculation times, while no difference was observed for Pst $\triangle h r c C \triangle C F A$ (Figure 5E). Transcriptional regulation processes seemed to be reduced in all three strains at 168 hours post-inoculation (hpi), and so did two-component system expression (Supplementary Tables $S 2 A, S 2 B, S 2 C$ and Figure $5 \mathrm{D}$ and $5 E$ ), perhaps because processes involved in sensing and responding to the plant environment are more important during the initial interaction of the microbe with its host. Only in the microbiota endophytes were genes involved directly in transcription, such as the different RNA polymerase subunits, expressed higher after $168 \mathrm{hpi}$. For both Pst $\triangle h r c C \triangle C F A$ and Achromobacter, flagellum biosynthesis was lower in plants when compared to the inoculum, and these genes were down-regulated even further as time inside plants went by 
(Supplementary Tables S2A and S2B and Supplementary Figure S6). Flagellum biosynthesis repression may be reflective of the strong pressure that flagellin detection by plants has over microbiota adaptation (Colaianni et al. 2021).

As secondary metabolites can be responsible for regulating microbe-microbe and plantmicrobe interactions, we used antiSMASH (Blin et al. 2019) to identify potential secondary metabolite biosynthesis clusters in all three phyllosphere-inhabiting bacteria (Supplementary Table S3). The analysis confirmed the presence of known secondary metabolite clusters in Pseudomonas syringae, such as those for the biosynthesis of the phytotoxin coronatine and the siderophores pyoverdin and yersiniabactin. Other than those three clusters, a region involved in the biosynthesis of the dipeptide $\mathrm{N}$-acetylglutaminylglutamine amide (NAGGN) showed a clear and stable up-regulation inside plants (Supplementary Table S3A). NAGGN might function in osmoregulation in Pseudomonas, as has already been shown in other bacteria (Sagot et al. 2010), and protect Pst $\triangle$ hrcC $\triangle$ CFA from osmotic stress. No differentially expressed biosynthetic clusters were observed in Pandoraea, while in A. xylosoxidans, expression of a cluster involved in the biosynthesis of the osmoprotectant ectoine was up-regulated in plants, especially early during plant colonization (Supplementary Table S3B). This result independently confirmed the findings of the biological pathway enrichment analysis done previously (Supplementary Tables S1C and S2B). A secondary metabolite cluster in $A$. xylosoxidans for the production of resorcinol, which could potentially have antimicrobial activity (Schöner et al. 2015), was induced early in the interaction of A. xylosoxidans with plants, perhaps because this metabolite confers competition advantages for growth for this microbiota strain. Finally, expression of genes predicted to be involved in the biosynthesis of a desferrioxamine-like siderophore was down-regulated inside plants in $A$. xylosoxidans, which suggests that this endophyte does not experience iron limitation, similar to what has been observed during pathogenic infections of Pst DC3000 inside plants (Jones and Wildermuth 2011).

\section{Non-pathogenic endophytes resemble more closely the physiological status of stationary- phase bacteria}

As the density of populations inside plants seems to not change for non-pathogenic bacterial endophytes (see Figure 1A, 1C and Supplementary Figure S1A), we hypothesized that bacteria could have entered a physiological status that closely resembles that of bacteria grown in vitro when they reach stationary phase. We observed that overall gene expression in vitro was more similar between each in vitro population (the inoculum, logarithmic and stationary populations) than with the overall gene expression observed inside plants (see PCAs in Supplementary Figures S5E and S5F). However, when we compared the bacterial processes of Pst $\Delta h r c C \Delta C F A$ that were 
enriched for up- and down-regulated genes inside plants with populations of cells that were grown in vitro to logarithmic and stationary phase (Supplementary Tables S1A and S1B), bacterial populations that were actively dividing and had reached logarithmic phase were different from populations in stationary phase or from bacterial populations that had been inside plants for 168 hours (7 days; Figures 6A and 6B). Not only that, but the majority of different biological processes between logarithmic and stationary populations were the same as those observed between logarithmic populations and at $168 \mathrm{hpi}$. Protein translation, and generation of metabolite precursors and energy processes were down-regulated in stationary phase and after $168 \mathrm{hpi}$, while virulencepromoting mechanisms, flagellum biosynthesis, and two-component systems were up-regulated when compared to logarithmic phase populations. This reinforces the idea that bacteria inside plants more closely resemble in vitro bacteria that have reached stationary phase, and correlates with their inability to increase in population density inside plants.

\section{Bacterial gene expression of select biological processes during long-term adaptation of a non-pathogen inside plants}

We decided to corroborate the RNA-Seq results by performing qRT-PCR of select genes. We selected genes involved in virulence (the sigma factor master regulator of virulence hrpL; Lam et al. 2014, and the type III effector avrPto; Nguyen et al. 2010), transcription (the housekeeping RNA polymerase sigma factor $r p o D$; Feklístov et al. 2014), and bacterial cell division (ftsZ; McQuillen and Xiao 2020). For avrPto, $h r p L$, and $r p o D$, gene expression was extremely low in the inoculum, increased exponentially by 6 hours after inoculation into plants, and then decreased over time, with the lowest level by 168 hours (Figure 7A and Supplementary Figure S8A). For example, the expression of $r p o D$ at 6 hours post-inoculation was almost 200 times greater than in the inoculum, and 6 times greater than the expression at 168 hours. rpoD has been used in the past as a qPCR reference gene (Smith et al. 2018); however, its expression, at least under certain conditions, is too variable for this purpose, as observed in our experiments. fts $Z$ showed the same trend of early increased expression and subsequent decrease in planta; however, the relative expression in the inoculum was more variable (Figure 7A and Supplementary Figure S8B). Overall, qRT-PCR results were in agreement with the transcriptome results for the above-mentioned three biological processes.

\section{Bacterial gene expression in ETI-causing interactions is similar to that observed for non- pathogens}

As both non-pathogens and ETI-causing bacterial strains had the same apparent population stasis in plants (see Figures $1 \mathrm{~A}$ and 1B), we evaluated gene expression for Pst DC3000 after AvrPto 
recognition (via RPS7 in Bu-22 plants) for the same genes described in the previous section to try to understand if gene expression was similarly affected. Initially, we tried using a high inoculum for this experiment, similar to was used for Pst $\triangle h r c C \triangle C F A$. However, even though a faster hypersensitive response is observed at a high inoculum in Bu-22 plants (Velásquez et al. 2017), ETI restriction of bacterial multiplication is compromised (Supplementary Figure S8C). As such, we decided to use a lower inoculum for evaluating gene expression in an incompatible interaction (Supplementary Figure S8D). We also started measuring gene expression 1 day after inoculation and not at 6 hours, as in ETI interactions, there is usually a small initial growth of the microbe before population stasis (Figure 1B and Supplementary Figure S1B).

The same gene expression pattern as that observed with Pst $\triangle h r c C \triangle C F A$ was observed under ETI conditions with Pst DC3000 for avrPto, hrpL, rpoD, and ftsZ (Figure 7B and Supplementary Figures S8B and S8E), with the highest expression for each of these genes observed at 24 hours after inoculation into Bu-22 plants, and then decreasing afterwards. As we were unable to perform RNA-Sequencing of ETI-inducing strains to characterize population stasis using a high inoculum (see the explanation above), we evaluated the expression of a few additional genes under ETI conditions: an additional gene involved in virulence (the phytotoxin biosynthesis gene coronafacate ligase cfl; Worley et al. 2013, which is deleted in Pst $\Delta$ hrcC $\Delta C F A$ ), a gene involved in last step of the Entner-Doudoroff pathway (the pyruvate kinase pyk; Schormann et al. 2019), and a gene involved in protein translation (tRNA ${ }^{\text {fMet }}$-formyl transferase fmt, which formylates the initiator tRNA ${ }^{f M e t}$ that carries the first amino acid used in protein translation in Eubacteria; Laursen et al. 2005). Expression of these three genes showed a similar pattern to that observed previously; gene expression was very low in the inoculum, increased by 24 hours after inoculation, and decreased at later time points (Supplementary Figure S8E).

\section{DISCUSSION}

In this study, we characterized the population dynamics behind bacterial endophyte survival and multiplication, and used transcriptomics to infer the biological processes important for microbial multiplication. We observed that long-term population densities of phyllosphere-inhabiting bacteria seemed to remain static over time. This bacterial population stasis lasted for several weeks and was observed for both ETI-inducing and non-pathogenic microbes. We decided to study this bacterial population stasis phenomenon by using a combination of fluorescent reporters, antibiotics targeting dividing bacteria, and in planta transcriptomics. The apparent prevalent population stasis was caused by equilibrium in the rates of multiplication and death of the microbe, and likely not by lack of sufficient resources or of an appropriate niche for microbial growth. In 
planta transcriptomes of bacterial endophytes suggested that their physiology more closely resembles the physiology that bacteria experience during stationary phase, a condition in which there is selective transcription of certain biological processes and in which stress responses are more active.

We observed that microbiota population density numbers were in apparent stasis, with the immune system unable to eliminate (or perhaps sometimes even detect) bacterial endophytes. Even if phyllosphere endophytes are in a stationary-like state, this does not mean that bacteria are not metabolically active, irrespective of the lack changes in their population density numbers. Bacteria in stationary phase are not inert; for example, during stationary phase protein expression is constant (Gefen et al. 2014). Also, it is during such phase that secondary metabolites, such as osmoprotectants and competition-facilitator antibiotics, are synthesized (Navarro Llorens et al. 2010). Bacteria are usually in a nutrient-deprived stationary state in nature, as abundant resources are a rare occurrence. Population stasis at high bacterial densities suggests that it is not a lack of resources that prevents non-pathogenic endophytes at low densities from multiplying and increasing their numbers once they are inside leaves (Figure 2A). Commensal phyllosphere bacteria might have evolved to maintain low population numbers via a slow multiplication rate that matches the death rate, in order to not alert the immune system of their presence, as would occur during the colonization of a pathogen-which normally would carry immune-dampening mechanisms. Most likely, long-term evaluation of phyllosphere bacteria, in contrast to previous reports that focused on the early events after infections, are more likely reflective of the commensal experience in nature.

Even four weeks after the initial inoculation, and after a significant growth of the inoculated plants had occurred (see Figure $1 \mathrm{~A}$ ), the endophytic population densities remained stable, almost as if the plants were not affected by the presence of such microbes. This makes us wonder if there

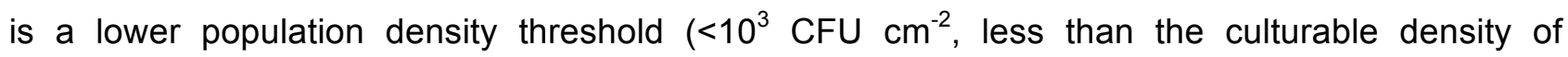
endophytes recovered from leaves; Chen et al. 2020b, Xin et al. 2016) that would allow for unrestricted growth of microbiota needed for seedling colonization by microbes in nature. Regarding an upper population density in which the immune system becomes activated to eliminate the invading endophytes, no such threshold was observed (Figure 2A), except at

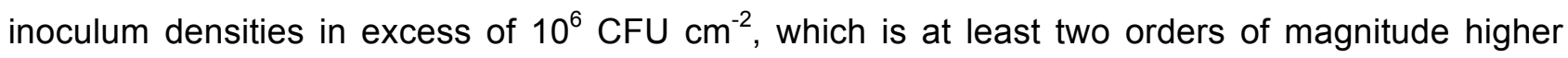
than naturally observed endophyte densities (and even then, the population density was reduced

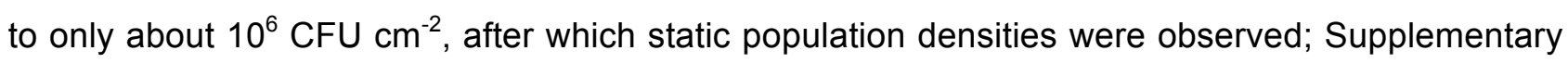
Figures S5A, S5B, and S5C). The only bacterial strain for which apparent population stasis was not observed was $P$. fluorescens $0-1$. This bacterium was originally isolated from soil (Silby et al. 2009), and perhaps lacks the adaptation mechanisms to survive as a leaf endophyte. Another 
possibility would be for $P$. fluorescens 0-1 to carry a MAMP that would trigger such a strong PTI response in Arabidopsis that the population density would be reduced (at an inoculum of $10^{8} \mathrm{CFU}$ $\mathrm{mL}^{-1}$, inoculation of $P$. fluorescens into Arabidopsis Col-0 causes cell death; $A$. Velásquez, unpublished).

During ETI interactions, apparent population stasis is also observed, phenocopying the response observed for microbiota bacteria lacking virulence mechanisms. Population density stasis was observed after activation by both NLRs (NOD-like receptors) of the coiled-coil and TIR classes of Resistance proteins (RPS2 and RPS5 are of the coiled-coil class, while RPS4 is a TIR NLR; Cui et al. 2015), suggesting that this phenomenon is widespread. The initial growth observed for ETIinducing strains in the first day after inoculation implies that the ETI-mediated population restriction mechanisms have not kicked in. In the host-pathogen battle experienced by ETI-inducing bacteria, the initial gains by bacterial virulence mechanisms seem to be outdone by the plant immune system at later time points. Additionally, niche destruction caused by the hypersensitive response of the cells undergoing effector recognition is not enough to eliminate bacteria. Having potential pathogenic populations always present in plants undergoing ETI suggests that these plants could serve as potential reservoirs for the infection of nearby plants not carrying the corresponding $R$ genes. This could have implications for disease management during agricultural production, assuming that bacteria could be disseminated from plants undergoing ETI.

Gene expression in Pst DC3000 after plants undergo ETI showed a pattern reminiscent of the one observed for non-pathogenic Pst $\triangle$ hrcC $\triangle$ CFA (Figures 7A and 7B). Under ETI conditions, there was a dramatic reduction of expression over time inside plants of genes involved in virulence: for the type III effector avrPto, the coronatine biosynthesis gene cfl, and the master regulator of virulence hrpL (Figures $7 \mathrm{~B}$ and Supplementary Figure S8E). The down-regulation of avrPto expression, which in RPS7-carrying plants betrays Pseudomonas syringae by alerting plants of its presence, might be an adaptation to quench the strong immune response experienced by bacteria during ETI, and "transform" Pst DC3000 into a non-pathogenic persisting microbe, or it might occur due to a lack of type III secretion system-inducing compounds present in the plant apoplast during ETI.

Transcriptomes of all three phyllosphere-inhabiting bacteria, Achromobacter, Pandoraea and Pst $\triangle h r c C \triangle C F A$, showed that the expression of the machinery for protein translation and for the generation of energy and intermediate metabolites was up-regulated inside plants when compared to the inoculum, which was grown in vitro. Once bacteria were in the apoplast, the above-mentioned processes had a higher expression for the two microbiota endophytes the longer bacteria resided in the apoplast, perhaps suggesting that they have a better adaptation than Pst $\triangle h r c C \triangle C F A$ for long-term survival inside plants, especially as this non-pathogen has been 
disarmed for its main adaptation mechanisms for apoplast survival: the virulence-promoting type III effectors and coronatine. The phyllosphere bacteria have adapted to colonize the apoplast, and as such, there was an induced expression of mechanisms involved in the response to stress, while the expression of genes putatively involved in the biosynthesis of secondary metabolites was upregulated, including two clusters that synthesize osmoprotectants: $\mathrm{N}$-acetylglutaminylglutamine for Pst $\triangle h r c C \triangle C F A$, and ectoine for $A$. xylosoxidans.

The apparent population stasis in non-pathogenic microbiota was caused by bacterial multiplication and death at equivalent rates, as demonstrated by the killing of any bacteria that attempted to divide under $\beta$-lactam antibiotic treatment (Figure 3B and Supplementary Figures S3B and $\mathrm{S} 3 \mathrm{C}$ ). This was further confirmed using a division fluorescent reporter in Pst $\triangle h r c C \triangle C F A$ (Figure 4D and 4E). In immune-activated tissue, there is a transient non-lethal effect against virulent bacteria; this physiological state can easily be reversed if the proper environmental conditions are met (Figure 2C and Supplementary Figure S2D). It was also apparent that there is phenotypic heterogeneity of the clonal population of microbiota: some bacteria are physiologically able to multiply (depending on the environmental conditions, up to $98 \%$ of the population), while others are in a quiescent state, almost equivalent to being in stationary phase. Understanding the cues for multiplication and stasis of in planta bacterial populations could be used to manipulate pathogenic microbes into entering a stationary state and not causing disease. This might require adaptation and optimization of current techniques for single-cell bacterial RNA-Seq (Blattman et al. 2020, Kuchina et al. 2021) for use in future in planta transcriptomics aimed to better understand phenotypic heterogeneity.

Both the transcriptome of Pst $\triangle h r c C \triangle C F A$ and their in planta bacterial population density numbers (Figures $1 \mathrm{~A}$ and 6 ) implied that bacteria were experiencing a physiological state that closely resembled the one that bacteria would experience in stationary phase. Additionally, it could well be that the physiology of pathogenic microbes, at least before reaching the plant's carrying capacity, resembles that of bacteria in logarithmic phase-except for the activation of virulence mechanisms, which occurs only inside the host. Expression of the RNA polymerase sigma factor involved in adaptation to stationary phase physiological conditions, rpoS, showed almost no change at $168 \mathrm{hpi}$ or stationary phase, compared to the expression observed in logarithmic-phase bacterial populations (Supplementary Table S4A). This could reflect a more important role of posttranscriptional regulation in modifying rpoS activity in $P$. syringae (Jaishankar and Srivastava 2017). By contrast, the mRNA expression of two other regulators of stationary phase, relA and spoT, involved in the bacterial stringent response (by synthesizing and degrading guanosine tetra and pentaphosphate [(p)ppGpp)]; Jaishankar and Srivastava 2017), was down-regulated in both stationary phase and in planta after $168 \mathrm{hpi}$ compared to the expression in logarithmic phase 
(Supplementary Table S4A). This result reinforces the idea that long-term bacteria inside plants resemble stationary-phase populations of bacteria.

Microbiota endophytes seem to be in a stationary-like phase physiological state, one in which their population density numbers are in equilibrium, possibly to not alert the plant immune system of their presence. By no means does this imply that bacteria are in a quiescent state; while the population density might not change, the bacteria are still metabolically active and adapting to their surrounding environment. A better understanding of the nature of the population dynamics and transcriptomic features associated with a commensal lifestyle sets a foundation for future engineering of commensal microbiota in agricultural settings.

\section{MATERIALS AND METHODS}

All experiments reported in this study were done at least thrice, except for the RNA-Sequencing experiments.

\section{In vitro bacterial growth and antibiotics used}

Supplementary Table S5 lists the bacterial strains used in this study. Escherichia coli strains were grown in LB (Lennox) medium at $37^{\circ} \mathrm{C}$, while all other strains were grown in either a modified LB medium (LM: $10 \mathrm{~g} \mathrm{~L}^{-}$ 1 tryptone, $6 \mathrm{~g} \mathrm{~L}^{-1}$, yeast extract, $1.5 \mathrm{~g} \mathrm{~L}^{-1}, \mathrm{KH}_{2} \mathrm{PO}_{4}, 0.6 \mathrm{~g} \mathrm{NaCl}$, and $0.4 \mathrm{~g} \mathrm{MgSO}_{4} \bullet 7 \mathrm{H}_{2} \mathrm{O}$ ) or King's $\mathrm{B}$ medium at $30^{\circ} \mathrm{C}$.

Antibiotics and derivatives were used at the following concentrations: $100 \mu \mathrm{g} \mathrm{mL}^{-1}$ ampicillin, $67-80$ $\mathrm{ng} \mathrm{mL}{ }^{-1}$ anhydrotetracycline, $400 \mu \mathrm{g} \mathrm{mL}^{-1}$ carbenicillin, $400 \mu \mathrm{g} \mathrm{mL}^{-1}$ cefotaxime, $75 \mathrm{\mu g} \mathrm{mL}^{-1}$ cycloheximide (to prevent fungal growth), 1-15 $\mu \mathrm{g} \mathrm{mL}^{-1}$ gentamycin, $50 \mu \mathrm{g} \mathrm{mL}^{-1}$ kanamycin, $100 \mu \mathrm{g} \mathrm{mL}^{-1}$ rifampicin, and $50 \mu \mathrm{g}$ $\mathrm{mL}^{-1}$ spectinomycin. Diaminopimelic acid (DAP) was used at a concentration between $200-400 \mu \mathrm{gL}^{-1}$. flg22, an epitope of bacterial flagellin and inducer of PAMP-triggered immunity (PTI), was used at a concentration of $500 \mathrm{nM}$.

To evaluate the response of logarithmic- and stationary-phase grown Pseudomonas syringae pv. tomato (Pst) $\triangle$ hrcC $\triangle C F A$ cultures to the antibiotic carbenicillin, bacteria were grown in liquid LM overnight at $30{ }^{\circ} \mathrm{C}$. For logarithmic-phase samples, overnight bacterial suspensions were diluted with $\mathrm{LM}$ to $10^{8} \mathrm{CFU} \mathrm{mL}^{-}$

${ }^{1}$, and grown for 4 hours before antibiotic treatment. Stationary-phase samples were not diluted. $\mathrm{H}_{2} \mathrm{O}$ control or $400 \mu \mathrm{g} \mathrm{mL}^{-1}$ carbenicillin were added to the cultures and grown for over 3 days. Before plating serial dilutions of the samples to determine population densities, cultures were washed twice with $0.25 \mathrm{mM} \mathrm{MgCl} 2$ to remove any trace of the antibiotic from the bacterial suspension.

\section{Plant growth conditions}

Arabidopsis plants were grown in a growth chamber with the following conditions: 12-hour day length, 80 $\mu$ moles $\mathrm{m}^{-2} \mathrm{~s}^{-1}$ of photon flux, a temperature of $24.5^{\circ} \mathrm{C}$ during the day and $23.0^{\circ} \mathrm{C}$ during the night, and a relative humidity between $65 \%$ and $75 \%$. Supplementary Table S6 lists the plant material used for this study. 
For Supplementary Figure 3B, and for the in planta RNA-Seq samples of Achromobacter and Pandoraea (Supplementary Figures $5 B$ and $5 C$ ), the relative humidity was increased to $99 \%$ after bacterial inoculation. Seeds were stratified for 2 to 5 days before sowing. Plants were watered with one-half strength Hoagland's solution when needed. All plants were grown under a partially covered transparent plastic dome.

\section{Bacterial population density quantification assays}

Bacterial inoculum suspensions were prepared from cultures grown in plates to stationary phase. Bacteria were resuspended in $0.25 \mathrm{mM} \mathrm{MgCl} 2$ to the appropriate $\mathrm{OD}_{600}$, after which they were infiltrated using a needleless syringe into the abaxial side of Arabidopsis leaves. To determine the in planta population density numbers, leaf-disc punches were collected from plants and ground in $250 \mu \mathrm{L}$ of $10 \mathrm{mM} \mathrm{MgCl}$ using the TissueLyser II (QIAGEN; 2 cycles of 30 seconds at $25 \mathrm{~Hz}$ ) and 3-mm zirconium oxide beads (Glen Mills Inc.). Serial dilutions of the ground tissue were spotted onto plates with the appropriate antibiotics and grown overnight. Colony forming units (CFUs) per $\mathrm{cm}^{2}$ were determined for each sample, while CFUs per $\mathrm{mL}$ were determined for each inoculum.

To determine endophytic bacterial populations, leaves were placed in a $0.825 \%$ sodium hypochlorite solution for 1 minute, and then washed twice in distilled $\mathrm{H}_{2} \mathrm{O}$ for a minute. Leaves were blotted dry, after which leaf discs were collected as described above.

To recover bacteria from leaves to use as inoculum, leaf discs were collected and ground in $0.25 \mathrm{mM}$

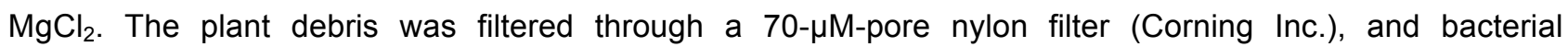
suspensions were washed twice in $0.25 \mathrm{mM} \mathrm{MgCl}_{2}$ at $4,000 \mathrm{~g}$ for 5 minutes. For plant inoculation, DMSOprimed recovered bacteria were diluted 100 times, while flg22-primed recovered bacteria were diluted 5 times, to achieve equivalent inoculum numbers.

To prime plant defenses with flg22, 20 to 22 hours before bacterial inoculation, leaves were infiltrated with mock $0.005 \%$ DMSO or with $500 \mathrm{nM}$ of the PTI inducer flg22.

For in planta antibiotic treatments, $400 \mu \mathrm{g} \mathrm{mL}^{-1}$ of one of two $\beta$-lactam antibiotics, carbenicillin or cefotaxime, was infiltrated into plants every day until the end of the experiment starting at 1 day postinoculation with the respective bacterial endophyte. $\mathrm{H}_{2} \mathrm{O}$ was used as a mock control.

\section{Cloning}

The dual fluorescent division reporter pUC18-mini-Tn7T-Gm::tetR(BD)- $P_{\text {tet }}-m$ Citrine_mCerulean3-BCD2- $P_{14 g}$ was created in two steps. In the first step, a DNA fragment containing a strong transcriptional terminator, TpheA-1 (Chen et al. 2013), repressor tetR(BD) [sequence is the fusion of two alleles of tetR, carrying 50 codons of $\operatorname{tet} R(B)$ and the last 158 codons of $\operatorname{tet} R(D)$ (Kamionka et al. 2006)], the tetracycline promoter from E. coli Tn10 (which controls expression of both $\operatorname{tet}(B D)$ and $m$ Citrine; GenBank accession number AF162223), fluorescent protein mCitrine (Griesbeck et al. 2001), and two strong transcriptional terminators in opposite orientation, ECK125109870 and L3S2P56 (Chen et al. 2013), was synthesized by GenScript ${ }^{\circledR}$. This DNA fragment was cloned into pUC18-mini-Tn7T-Gm (Choi \& Schweizer 2006; cut with Nsil and Stul [New England Biolabs ${ }^{\circledR}$, Inc.]) using Gibson assembly. 
In the second step, two DNA fragments were PCR amplified using primer pairs AVL003 and AVL004, and AVL005 and AVL006 (Supplementary Table S7): one amplicon included the promoter P14g and translational coupler BCD2 from plasmid pBG42 (Zobel et al. 2015), while the other amplicon included the gene coding for the fluorescent protein mCerulean3 (Markwardt et al. 2011). These fragments were introduced into the previously generated intermediate plasmid (after cutting the plasmid with Spel [New England Biolabs $®$, Inc.]) by Gibson assembly to generate the division reporter pUC18-mini-Tn7T$\mathrm{Gm}:: \operatorname{tet} R(B D)-P_{\text {tet }}-m$ Citrine_mCerulean3-BCD2- $P_{14 g}$.

\section{Gene integration into the Pseudomonas genome}

Integration into the Pseudomonas genome was performed by site-specific transposition by $\mathrm{Tn} 7$ into the unique attTn7 site of Pst DC3000. For this, triparental mating was set up between the Pseudomonas recipient strain, the strain containing the transposase helper plasmid pTNS3 (Choi et al. 2008), and the $E$. coli RHO5 donor strain (Kvitko et al. 2012; carrying plasmids pBG42_mod or pUC18-mini-Tn7T-Gm with the genes to be integrated). Three to six days after conjugation and selection in plates containing $1.5 \mu \mathrm{mL}^{-1}$ of gentamycin, colony PCRs were set up to identify the putative transconjugants using three primer pairs: AVL007 and AVL008, AVL009 and AVL010, and AVL007 and AVL009 (Supplementary Table S7).

\section{Confocal microscopy}

Images were taken using the Nikon A1Rsi confocal microscope with a 20X objective (numerical aperture of 0.7 and a pinhole of 1.2 airy units). Both the CFP and YFP channels are detected using gallium arsenide phosphide photomultiplier (PMT) detectors. For the CFP channel, an excitation of $443.6 \mathrm{~nm}$ and an emission between 467 to $502 \mathrm{~nm}$ were used. For the YFP channel, an excitation of $513.9 \mathrm{~nm}$ and an emission of 530 to $600 \mathrm{~nm}$ were used. Images were acquired at a gain and offset at which the negative control (Arabidopsis plants infected with non-fluorescent Pst DC3000 or Pst $\triangle h r c C \Delta C F A$ ) had no signal being detected.

\section{RNA extraction}

Frozen plant tissue was ground using the TissueLyser II (QIAGEN; 2 cycles of 30 seconds at $27 \mathrm{~Hz}$ ) and 3$\mathrm{mm}$ zirconium oxide beads (Glen Mills Inc.). RNA was extracted using TRIzol ${ }^{\mathrm{TM}}$ (Thermo Fisher Scientific) and the Direct-zol RNA miniprep kit (Zymo Research), using a 30-minute on-column treatment with $12 \mathrm{U}$ of DNase I. A second DNase I treatment to remove all residual genomic DNA was performed using $30 \mathrm{U}$ of recombinant DNase I (Roche) and $10 \mathrm{U}$ of Protector RNase inhibitor (Roche) for 1 hour at $37^{\circ} \mathrm{C}$. RNA was purified a second time using TRIzol ${ }^{\mathrm{TM}}$ and the Direct-zol RNA miniprep kit.

To prepare logarithmic- and stationary-phase grown Pst $\triangle h r c C \triangle C F A$ cultures for RNA extraction, bacteria were grown in liquid $\mathrm{KB}$ overnight at $30{ }^{\circ} \mathrm{C}$. For logarithmic-phase samples, overnight bacterial suspensions were diluted with $\mathrm{KB}$ to $10^{8} \mathrm{CFU} \mathrm{mL}{ }^{-1}$ and grown for 6 hours. Stationary-phase samples were not diluted and grown for 6 additional hours.

To extract RNA from bacterial cultures grown in vitro, $10^{9} \mathrm{CFUs}$ of bacteria were resuspended in 150 $\mu \mathrm{L}$ of buffer TE (10 mM Tris-HCl, $1 \mathrm{mM}$ EDTA, $\mathrm{pH} 8.0$ ) with $5 \mathrm{mg} \mathrm{mL}^{-1}$ of lysozyme (Roche) for 5 minutes at 
room temperature. For the in vitro liquid-grown logarithmic- and stationary-phase bacteria, an extra step that used the RNA stabilizer RNAprotect Bacteria Reagent (QIAGEN), was used before the addition of lysozyme. After incubation with lysozyme, $400 \mu \mathrm{L}$ of buffer RLT (QIAGEN) were added to the suspension, which was then applied through QIA shredder columns (QIAGEN). The eluate was used for RNA purification using the RNeasy mini kit (QIAGEN). The only modification to the protocol of the kit was the extension of the on column DNase I (QIAGEN) digestion to 30 minutes. After RNA purification, a second DNase I treatment and purification using the Direct-zol RNA miniprep kit was performed as described above.

To check for the presence of genomic DNA (gDNA) contamination in the RNA samples, a PCR using 50-100 ng of RNA was performed using primers AVL011 and AVL012 (to check for Pst gDNA contamination), AVL013 and AVL014 (to check for Pandoraea sp. Col-0-28 gDNA contamination), AVL015 and AVL016 (to check for Achromobacter xylosoxidans sp. Col-0-50 gDNA contamination), and AVL017 and AVL018 (to check for $A$. thaliana gDNA contamination) (Supplementary Table S7).

\section{cDNA preparation and Quantitative Reverse transcriptase-PCR (qRT-PCR)}

Three-hundred $\mathrm{ng}$ to two $\mu \mathrm{g}$ of RNA were used to prepare cDNA using $2.5 \mu \mathrm{M}$ of random hexamer primers (Integrated DNA Technologies, Inc.), $40 \mathrm{U}$ of Protector RNase inhibitor and $200 \mathrm{U}$ of M-MLV reverse transcriptase (Invitrogen ${ }^{\mathrm{TM}}$ ), following the protocol described by the manufacturer. Between 0.4 and $1 \mu \mathrm{L}$ of cDNA was used with appropriate primers (Supplementary Table S7) and SYBR® Green PCR master mix (Applied Biosystems) for qRT-PCR. Two technical replicates were done per sample. PCR was performed on the 7500 Fast Real-Time PCR System (Applied Biosystems ${ }^{\mathrm{TM}}$ ) using automatic $\mathrm{C}_{\mathrm{T}}$ threshold detection. Bacterial transcripts were normalized to the leuB (PSPTO_2175) reference gene using the $\Delta \mathrm{C}_{\mathrm{T}}$ method (Livak and Schmittgen 2001). In previous RNA-Seq experiments, leuB showed very little variability in expression under multiple conditions. The efficiency of all primer pairs was validated to be between 90 to $110 \%$. Amplicon melting curves had a single predominant peak.

\section{RNA-Sequencing and bioinformatic analysis}

RNA integrity was evaluated using the 2100 BioAnalyzer (Agilent Technologies, Inc.) and RNA concentration was determined with the Qubit ${ }^{\mathrm{TM}}$ RNA HS assay kit (Thermo Fisher Scientific). Libraries for RNA-Seq were prepared using the protocol described in Nobori et al. (2018), but using the newest iteration of the library preparation kit from NuGEN $\circledast$ (Tecan Genomics, Inc.), the Universal RNA-Seq with NuQuant $\circledast$ kit, and skipping the use of the MICROBEnrich kit. This protocol allows the removal of plant and bacterial rRNAs and of the most abundant Arabidopsis transcripts. Libraries were pooled and sequenced in the Illumina ${ }^{\circledR} \mathrm{HiSeq}$ 4000 using HiSeq 4000 SBS reagents to obtain single 50-bp reads. Base calling was done by Illumina Real Time Analysis (RTA version 2.7.7).

The read quality was evaluated with FASTQC (version 0.11.7; Andrews 2010), while adapters and low quality sequences were trimmed with Cutadapt (version 2.9; Martin 2011). Three different pipelines were used to calculate differential gene expression (DGE), as DGE varies depending on the models used for transcript estimation (Trapnell et al. 2013). In the first pipeline, reads were aligned to the reference genomes 
using HISAT2 (version 2.1.0; Kim et al. 2019). Aligned reads were processed using SAMTools (version 1.9; Li et al. 2009), after which StringTie (version 2.1.3; Kovaka et al. 2019) was used to calculate transcript frequency (average expression per treatment is shown on Supplementary Tables S4A, S4B, and S4C), to finally estimate DGE using DESeq2 (Love et al. 2014). On the second pipeline, reads were also aligned with HISAT2, but this time DGE was calculated directly using Cuffdiff (version 2.2.1; Trapnell et al. 2013). In the third pipeline, reads were pseudo-aligned using Salmon (version 0.11.3 for Pst $\triangle$ hrcC $\triangle C F A$ or 1.2 .1 for the other two endophytes; Patro et al. 2017), after which DESeq2 was performed for DGE.

Principal component analysis (PCA) of transcript reads after DESeq2 analysis used the rlog and plotPCA functions of DESeq2 in Rstudio (version 1.3.1093). Significantly up- or down-regulated genes were identified as those in any of the three pipelines in which the absolute value of the logarithm (in base 2) of the fold change was greater than 0.58 , and the adjusted $p$ value of the statistical test was lesser than 0.05 . GO (gene ontology) analysis used the Cytoscape application BINGO (version 3.0.4; Maere et al. 2005); these GO results were summarized with REVIGO (Supek et al. 2011), after which manual curation of the enriched pathways was done. PaintOmics 3 (version 0.4.5; Hernández-de-Diego et al. 2018) was used for initial visualization of Pst $\triangle h r c C \triangle C F A$ gene expression in biological pathways. We used antiSMASH (version 6.0.0; Blin et al. 2019) to identify clusters of genes predicted to be involved in the production of secondary metabolites.

STEM (Short-Time series Expression Miner; version 1.3.13; Ernst and Bar-Joseph 2006) analysis was used to look for enriched patterns of expression over time between the samples collected for the inoculum, 6, 24, and 168 hours post-inoculation (hpi) into Col-0 plants. Analysis used the logarithmically (in base 2) normalized expression data obtained from StringTie. GO pathway enrichment analysis used the BINGO application, and summarization of the results was done as described above.

Orthologous gene groups between the three bacterial strains were identified using OrthoMCL (Li et al. 2003). Each orthologous group may have more than one gene from each strain. Genes that had the same pattern of differential up- or down-regulation for a comparison between two treatments in one, two or all three strains were identified. We only compared the inoculum or $6 \mathrm{hpi}$ with $168 \mathrm{hpi}$, as we expected these two comparisons to be the most significant for the long-term adaptation of phyllosphere microbiota to plants. Biological process enrichment analysis of orthologous groups used the Pst $\triangle h r c C \triangle C F A$ gene belonging to such group for the analysis when available.

The reference genomes used for analysis are those from Pst DC3000: GenBank accession AE016853.1 for the genomic DNA, and GenBank accessions AE016855.1 and AE016854.1 for the two plasmids; for Achromobacter xylosoxidans Col-0-50 and Pandoraea sp. Col-0-28, the genome sequences are under the BioProject PRJNA555902 in the Sequence Read Archive data, sample runs SRR9732406 and SRR9732397, respectively. Reference databases for GO analysis for Achromobacter and Pandoraea were created using InterProScan (version 5.47-82.0).

Graphs and statistical analysis were performed using Prism (version 6.0b) or Rstudio (Bubble graphs and Venn diagrams). Upset plots and the heatmaps for Figures 5D and 5E were graphed using TBTools (version 1.0; Chen et al. 2020a). 


\section{ACKNOWLEDGEMENTS}

We would like to thank Dr. Melinda Frame for her help using the confocal microscope; Cody Keilen and James Klug for their help maintaining the growth chambers; Dr. Kevin Childs, Dr. Jie Wang, Dr. James Kremer, and OE Biotechnology (China) for their bioinformatics expertise; Dr. Brian Kvitko for suggesting using carbenicillin for killing dividing bacteria; the undergraduate students at the He laboratory for preparing laboratory and growth chamber materials; and Dr. Kyaw Aung, Dr. Jonghum Kim, and Dr. Anne Rea for critically reviewing the manuscript.

Funding for this study was provided by the United States National Institute of Health Al155441 grant (to SYH).

SUPPLEMENTARY INFORMATION

Supplementary References

Supplementary Figure S1. Endophytic bacterial populations experience stasis inside plants.

Supplementary Figure S2. Bacterial population stasis after priming disappears over time and is not determined by PAMP-triggered immunity.

Supplementary Figure S3. Equilibrium in bacterial multiplication and death causes apparent bacterial population stasis.

Supplementary Figure S4. Visualization of pathogenic Pseudomonas syringae (Pst) carrying the fluorescent division reporter on the surface of Arabidopsis leaves.

Supplementary Figure S5. Transcriptome and population analysis of three phyllosphereinhabiting bacteria.

Supplementary Figure S6. Expression of genes from select biological pathways for Pseudomonas syringae pv. tomato $\triangle$ hrcC $\triangle$ CFA.

Supplementary Figure S7. Number of shared and unique differentially expressed genes between the three analyzed phyllosphere-inhabiting endophytes. 
Supplementary Figure S8. In planta gene expression for non-pathogenic and effector triggered immunity-inducing bacteria show a similar response

Supplementary Table S1. Enriched biological processes of differentially expressed genes (DEG) in bacterial endophytes.

Supplementary Table S2. Enriched biological processes in significantly different expression profiles after STEM (Short-Time series Expression Miner) analysis

Supplementary Table S3. Secondary metabolite biosynthetic clusters whose expression is differentially regulated inside plants.

Supplementary Table S4. Average gene expression in bacterial endophytes.

Supplementary Table S5. Bacterial strains used in this study.

Supplementary Table S6. Plant genotypes used in this study.

Supplementary Table S7. Primer sequences used in this study.

\section{REFERENCES}

Anderson JC, Wan Y, Kim YM, Pasa-Tolic L, Metz TO, and Peck SC (2014) Decreased abundance of type III secretion system-inducing signals in Arabidopsis mkp1 enhances resistance against Pseudomonas syringae. Proc Natl Acad Sci USA 111: 6846-6851.

Andrews S (2010) FastQC: A Quality Control Tool for High Throughput Sequence Data. URL http://www.bioinformatics.babraham.ac.uk/projects/fastqc/

Balint-Kurti P (2019) The plant hypersensitive response: concepts, control and consequences. Mol Plant Pathol 20: 1163-1178.

Bertram R and Hillen W (2008) The application of Tet repressor in prokaryotic gene regulation and expression. Microb Biotechnol 1: 2-16.

Bezrutczyk M, Yang J, Eom JS, Prior M, Sosso D, Hartwig T, Szurek B, Oliva R, Vera-Cruz C, White FF, Yang B, and Frommer WB (2018) Sugar flux and signaling in plant-microbe interactions. Plant J 93: 675-685.

Blattman SB, Jiang W, Oikonomou P, and Tavazoie S (2020) Prokaryotic single-cell RNA sequencing by in situ combinatorial indexing. Nat Microbiol 5: 1192-1201. 
Blin K, Shaw S, Steinke K, Villebro R, Ziemert N, Lee SY, Medema MH, and Weber T (2019) antiSMASH 5.0: updates to the secondary metabolite genome mining pipeline. Nucleic Acids Res 47: W81-W87.

Bodenhausen N, Bortfeld-Miller M, Ackermann M, and Vorholt JA (2014) A synthetic community approach reveals plant genotypes affecting the phyllosphere microbiota. PLoS Genet 10: e1004283.

Chen YJ, Liu P, Nielsen AA, Brophy JA, Clancy K, Peterson T, and Voigt CA (2013) Characterization of 582 natural and synthetic terminators and quantification of their design constraints. Nat Methods 10: 659-664.

Chen C, Chen H, Zhang Y, Thomas HR, Frank MH, He Y, and Xia R (2020a) TBtools: An integrative toolkit developed for interactive analyses of big biological data. Mol Plant 13: 1194-1202.

Chen T, Nomura K, Wang X, Sohrabi R, Xu J, Yao L, Paasch BC, Ma L, Kremer J, Cheng Y, Zhang L, Wang N, Wang E, Xin XF, and He SY (2020b) A plant genetic network for preventing dysbiosis in the phyllosphere. Nature 580: 653-657.

Choi KH, and Schweizer HP (2006) mini-Tn7 insertion in bacteria with single attTn7 sites: example Pseudomonas aeruginosa. Nat Protoc 1: 153-161.

Choi KH, Mima T, Casart Y, Rholl D, Kumar A, Beacham IR, and Schweizer HP (2008) Genetic tools for select-agentcompliant manipulation of Burkholderia pseudomallei. Appl Environ Microbiol 74: 1064-75.

Colaianni NR, Parys K, Lee HS, Conway JM, Kim NH, Edelbacher N, Mucyn TS, Madalinski M, Law TF, Jones CD, Belkhadir Y, and Dangl JL (2021) A complex immune response to flagellin epitope variation in commensal communities. Cell Host Microbe 29: 635-649.

Cui H, Tsuda K, and Parker JE (2015) Effector-triggered immunity: from pathogen perception to robust defense. Annu Rev Plant Biol 66: 487-511.

Cunnac S, Chakravarthy S, Kvitko BH, Russell AB, Martin GB, and Collmer A (2011) Genetic disassembly and combinatorial reassembly identify a minimal functional repertoire of type III effectors in Pseudomonas syringae. Proc Natl Acad Sci USA 108: 2975-2980.

Deslandes L, Olivier J, Theulieres F, Hirsch J, Feng DX, Bittner-Eddy P, Beynon J, and Marco Y (2002) Resistance to Ralstonia solanacearum in Arabidopsis thaliana is conferred by the recessive $R R S 1-R$ gene, a member of a novel family of resistance genes. Proc Natl Acad Sci USA 99: 2404-2409.

Ellinger D, Naumann M, Falter C, Zwikowics C, Jamrow T, Manisseri C, Somerville SC, and Voigt CA (2013) Elevated early callose deposition results in complete penetration resistance to powdery mildew in Arabidopsis. Plant Physiol 161: 1433-1444.

Ernst J, and Bar-Joseph Z (2006) STEM: a tool for the analysis of short time series gene expression data. BMC Bioinformatics 7:191.

Fan J, Crooks C, Creissen G, Hill L, Fairhurst S, Doerner P, and Lamb C (2011) Pseudomonas sax genes overcome aliphatic isothiocyanate-mediated non-host resistance in Arabidopsis. Science 331: 1185-1188.

Feklístov A, Sharon BD, Darst SA, and Gross CA (2014) Bacterial sigma factors: a historical, structural, and genomic perspective. Annu Rev Microbiol 68: 357-376.

Gefen O, Fridman O, Ronin I, and Balaban NQ (2014) Direct observation of single stationary-phase bacteria reveals a surprisingly long period of constant protein production activity. Proc Natl Acad Sci USA 111: 556 - 561.

Griesbeck O, Baird GS, Campbell RE, Zacharias DA, and Tsien RY (2001) Reducing the environmental sensitivity of yellow fluorescent protein. Mechanism and applications. J Biol Chem 276: 29188-29194.

Hassani MA, Durán P, and Hacquard S (2018) Microbial interactions within the plant holobiont. Microbiome 6: 58.

Hernández-de-Diego R, Tarazona S, Martínez-Mira C, Balzano-Nogueira L, Furió-Tarí P, Pappas GJ Jr, and Conesa A (2018) PaintOmics 3: a web resource for the pathway analysis and visualization of multi-omics data. Nucleic Acids Res 46: W503-W509. 
Huot B, Yao J, Montgomery BL, and He SY (2014) Growth-defense tradeoffs in plants: a balancing act to optimize fitness. Mol Plant 7: 1267-1287.

Jaishankar J and Srivastava P (2017) Molecular basis of stationary phase survival and applications. Front Microbiol 8: 2000.

Jones AM, and Wildermuth MC (2011) The phytopathogen Pseudomonas syringae pv. tomato DC3000 has three highaffinity iron-scavenging systems functional under iron limitation conditions but dispensable for pathogenesis. $\mathrm{J}$ Bacteriol 193: 2767-2775.

Kamionka A, Majewski M, Roth K, Bertram R, Kraft C, and Hillen W (2006) Induction of single chain tetracycline repressor requires the binding of two inducers. Nucleic Acids Res 34: 3834-3841.

Kim D, Paggi JM, Park C, Bennett C, and Salzberg SL (2019) Graph-based genome alignment and genotyping with HISAT2 and HISAT-genotype. Nat Biotechnol 37: 907-915.

Kovaka S, Zimin AV, Pertea GM, Razaghi R, Salzberg SL, and Pertea M (2019) Transcriptome assembly from long-read RNA-seq alignments with StringTie2. Genome Biol 20: 278

Kuchina A, Brettner LM, Paleologu L, Roco CM, Rosenberg AB, Carignano A, Kibler R, Hirano M, DePaolo RW, and Seelig G (2021) Microbial single-cell RNA sequencing by split-pool barcoding. Science 371: eaba5257.

Kvitko BH, Bruckbauer S, Prucha J, McMillan I, Breland EJ, Lehman S, Mladinich K, Choi KH, Karkhoff-Schweizer R, and Schweizer HP (2012) A simple method for construction of pir+ Enterobacterial hosts for maintenance of R6K replicon plasmids. BMC Res Notes 5: 157.

Lam HN, Chakravarthy S, Wei HL, BuiNguyen H, Stodghill PV, Collmer A, Swingle BM, and Cartinhour SW (2014) Global analysis of the HrpL regulon in the plant pathogen Pseudomonas syringae pv. tomato DC3000 reveals new regulon members with diverse functions. PLoS One 9: e106115.

Laursen BS, Sørensen HP, Mortensen KK, and Sperling-Petersen HU (2005) Initiation of protein synthesis in bacteria. Microbiol Mol Biol Rev 69: 101-123.

Lee MH, Jeon HS, Kim SH, Chung JH, Roppolo D, Lee HJ, Cho HJ, Tobimatsu Y, Ralph J, and Park OK (2019) Ligninbased barrier restricts pathogens to the infection site and confers resistance in plants. EMBO J 38: e101948.

Li H, Handsaker B, Wysoker A, Fennell T, Ruan J, Homer N, Marth G, Abecasis G, Durbin R, and 1000 Genome Project Data Processing Subgroup (2009) The Sequence Alignment/Map format and SAMtools. Bioinformatics 25: $2078-2079$.

Li L, Stoeckert CJ Jr, and Roos DS (2003) OrthoMCL: identification of ortholog groups for eukaryotic genomes. Genome Res 13: 2178-2189.

Livak KJ, and Schmittgen TD. Analysis of relative gene expression data using real-time quantitative $P C R$ and the $2^{-\Delta \Delta C_{T}}$ method. Methods. 2001 Dec;25(4):402-8.

Love MI, Huber W, and Anders S (2014) Moderated estimation of fold change and dispersion for RNA-seq data with DESeq2. Genome Biol 15: 550.

Macho AP, Zumaquero A, Gonzalez-Plaza JJ, Ortiz-Martín I, Rufián JS, and Beuzón CR (2012) Genetic analysis of the individual contribution to virulence of the type III effector inventory of Pseudomonas syringae pv. phaseolicola. PLoS One 7: e35871.

Maere S, Heymans K, and Kuiper M (2005) BiNGO: a Cytoscape plugin to assess overrepresentation of gene ontology categories in biological networks. Bioinformatics 21: 3448-3449.

Markwardt ML, Kremers GJ, Kraft CA, Ray K, Cranfill PJ, Wilson KA, Day RN, Wachter RM, Davidson MW, and Rizzo MA (2011) An improved cerulean fluorescent protein with enhanced brightness and reduced reversible photoswitching. PLoS One 6: e17896.

Martin M (2011) Cutadapt removes adapter sequences from high-throughput sequencing reads. EMBnet.J 17: 10-12. 
McQuillen R and Xiao J (2020) Insights into the structure, function, and dynamics of the cacterial cytokinetic FtsZ-ring. Annu Rev Biophys 49: 309-341.

Morris CE, and Moury B (2019) Revisiting the concept of host range of plant pathogens. Annu Rev Phytopathol 57: 6390.

Navarro Llorens JM, Tormo A, and Martínez-García E (2010) Stationary phase in gram-negative bacteria. FEMS Microbiol Rev 34: 476-495.

Nguyen HP, Yeam I, Angot A, Martin GB (2010) Two virulence determinants of type III effector AvrPto are functionally conserved in diverse Pseudomonas syringae pathovars. New Phytol 187: 969-982.

Nobori T, Velásquez AC, Wu J, Kvitko BH, Kremer JM, Wang Y, He SY, and Tsuda K (2018) Transcriptome landscape of a bacterial pathogen under plant immunity. Proc Natl Acad Sci USA 115: E3055-E3064.

Patro R, Duggal G, Love MI, Irizarry RA, and Kingsford C (2017) Salmon provides fast and bias-aware quantification of transcript expression. Nat Methods 14: 417-419.

Sagot B, Gaysinski M, Mehiri M, Guigonis JM, Le Rudulier D, and Alloing G (2010) Osmotically induced synthesis of the dipeptide $\mathrm{N}$-acetylglutaminylglutamine amide is mediated by a new pathway conserved among bacteria. Proc Natl Acad Sci USA 107: 12652-12657.

Schöner TA, Kresovic D, and Bode HB (2015) Biosynthesis and function of bacterial dialkylresorcinol compounds. Appl Microbiol Biotechnol 99: 8323 - 8328.

Schormann N, Hayden KL, Lee P, Banerjee S, and Chattopadhyay D (2019) An overview of structure, function, and regulation of pyruvate kinases. Protein Sci 28: 1771-1784.

Silby MW, Cerdeño-Tárraga AM, Vernikos GS, Giddens SR, Jackson RW, Preston GM, Zhang XX, Moon CD, Gehrig SM, Godfrey SA, Knight CG, Malone JG, Robinson Z, Spiers AJ, Harris S, Challis GL, Yaxley AM, Harris D, Seeger K, Murphy L, Rutter S, Squares R, Quail MA, Saunders E, Mavromatis K, Brettin TS, Bentley SD, Hothersall J, Stephens E, Thomas CM, Parkhill J, Levy SB, Rainey PB, and Thomson NR (2009) Genomic and genetic analyses of diversity and plant interactions of Pseudomonas fluorescens. Genome Biol 10:R51.

Smith A, Lovelace AH, and Kvitko BH (2018) Validation of RT-qPCR approaches to monitor Pseudomonas syringae gene expression during infection and exposure to Pattern-triggered immunity. Mol Plant Microbe Interact 31: 410-419.

Spoering AL and Lewis K (2001) Biofilms and planktonic cells of Pseudomonas aeruginosa have similar resistance to killing by antimicrobials. J Bacteriol 183: 6746-6751.

Stoitsova SO, Braun Y, Ullrich MS, and Weingart H (2008) Characterization of the RND-type multidrug efflux pump MexAB-OprM of the plant pathogen Pseudomonas syringae. Appl Environ Microbiol 74: 3387-3393.

Supek F, Bošnjak M, Škunca N, and Šmuc T (2011) REVIGO summarizes and visualizes long lists of gene ontology terms. PLoS One 6: e21800.

Trapnell C, Hendrickson DG, Sauvageau M, Goff L, Rinn JL, and Pachter L (2013) Differential analysis of gene regulation at transcript resolution with RNA-seq. Nat Biotechnol 31: 46-53.

Velásquez AC, Oney M, Huot B, Xu S, and He SY (2017) Diverse mechanisms of resistance to Pseudomonas syringae in a thousand natural accessions of Arabidopsis thaliana. New Phytol 214: 1673-1687.

Wang W, Yang J, Zhang J, Liu YX, Tian C, Qu B, Gao C, Xin P, Cheng S, Zhang W, Miao P, Li L, Zhang X, Chu J, Zuo J, Li J, Bai Y, Lei X, and Zhou JM (2020) An Arabidopsis secondary metabolite directly targets expression of the bacterial type III secretion system to inhibit bacterial virulence. Cell Host Microbe 27: 601-613.

Worley JN, Russell AB, Wexler AG, Bronstein PA, Kvitko BH, Krasnoff SB, Munkvold KR, Swingle B, Gibson DM, and Collmer A (2013) Pseudomonas syringae pv. tomato DC3000 CmaL (PSPTO4723), a DUF1330 family member, is needed to produce L-allo-isoleucine, a precursor for the phytotoxin coronatine. J Bacteriol 195: 287-96. 
bioRxiv preprint doi: https://doi.org/10.1101/2021.05.10.443510; this version posted May 10, 2021. The copyright holder for this preprint (which

was not certified by peer review) is the author/funder, who has granted bioRxiv a license to display the preprint in perpetuity. It is made available under aCC-BY-NC-ND 4.0 International license.

Wright CA, and Beattie GA (2004) Pseudomonas syringae pv. tomato cells encounter inhibitory levels of water stress during the hypersensitive response of Arabidopsis thaliana. Proc Natl Acad Sci USA 101: 3269-3274.

Xin XF, Kvitko B, and He SY (2018) Pseudomonas syringae: what it takes to be a pathogen. Nat Rev Microbiol 16: 316328.

Xin XF, Nomura K, Aung K, Velásquez AC, Yao J, Boutrot F, Chang JH, Zipfel C, and He SY (2016) Bacteria establish an aqueous living space in plants crucial for virulence. Nature 539: 524-529.

Yu X, Lund SP, Scott RA, Greenwald JW, Records AH, Nettleton D, Lindow SE, Gross DC, and Beattie GA (2013) Transcriptional responses of Pseudomonas syringae to growth in epiphytic versus apoplastic leaf sites. Proc Natl Acad Sci USA 110: E425-E434.

Zipfel C, Robatzek S, Navarro L, Oakeley EJ, Jones JD, Felix G, and Boller T (2004) Bacterial disease resistance in Arabidopsis through flagellin perception. Nature 428: 764-767.

Zobel S, Benedetti I, Eisenbach L, de Lorenzo V, Wierckx N, and Blank LM (2015) Tn7-based device for calibrated heterologous gene expression in Pseudomonas putida. ACS Synth Biol 4: 1341-1351. 


\section{Figure 1}

A

- Pst $\Delta h r c C \Delta C F A$
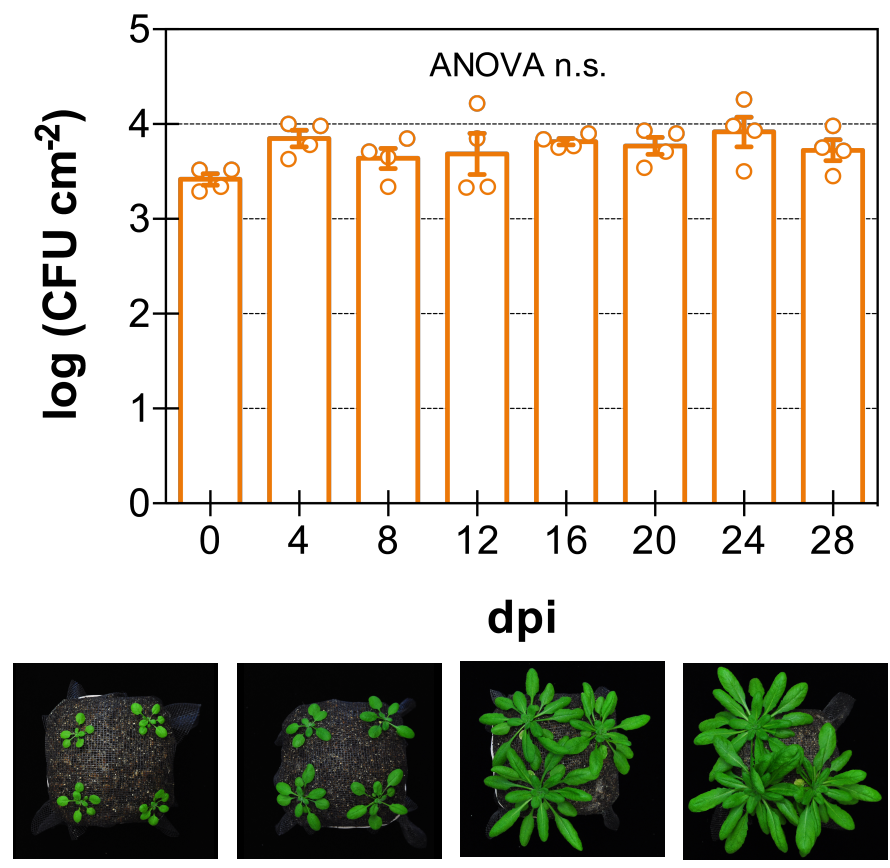

Day 0 Day 4 dpi

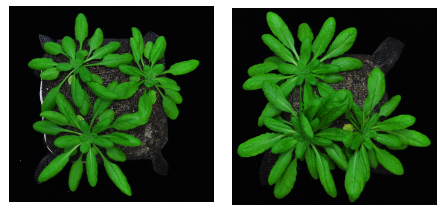

Day 12 Day 20
B

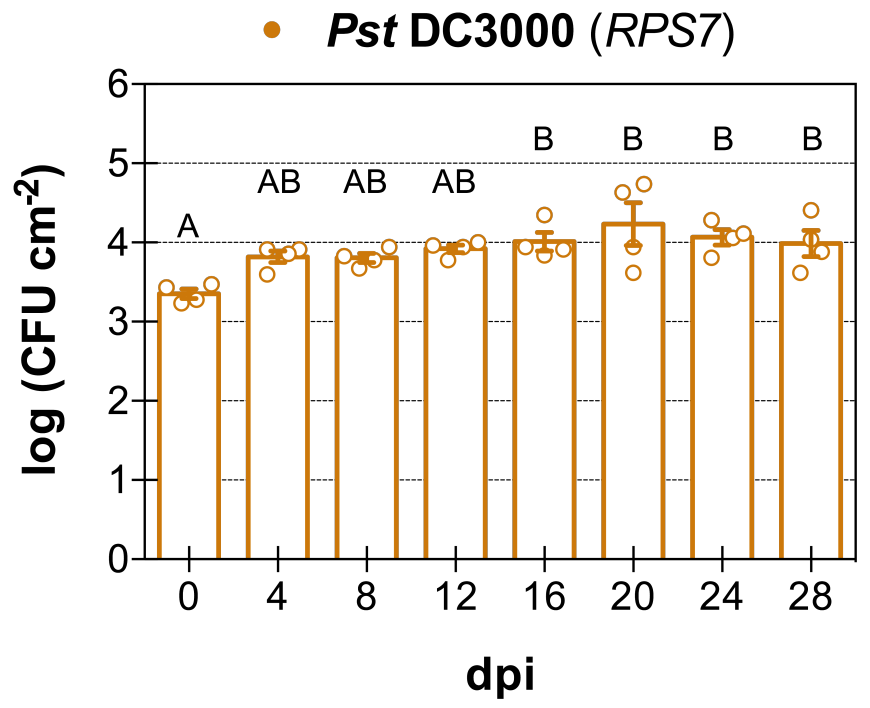

D

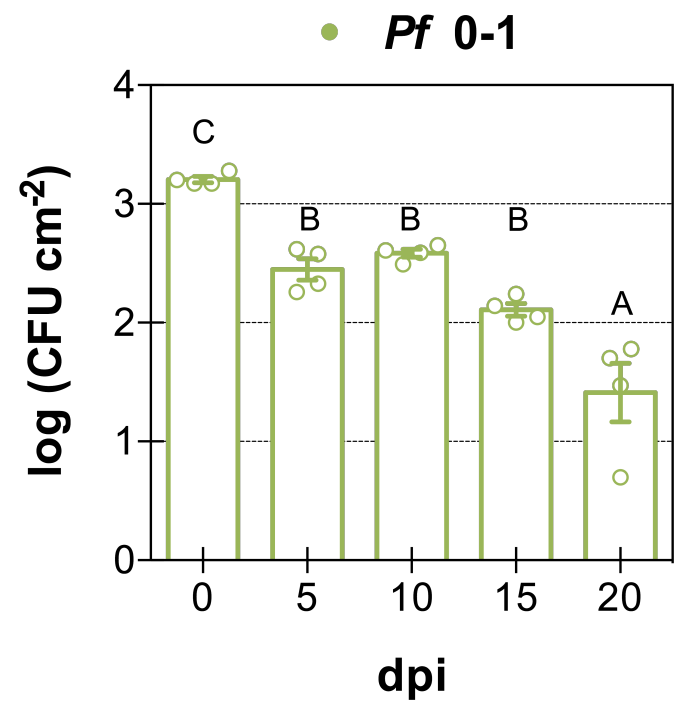


Figure 1. Non-pathogenic phyllosphere bacteria experience in planta bacterial population stasis. (A) Bacterial population density numbers of non-pathogenic $P$. syringae pv. tomato (Pst) $\triangle$ hrcC $\triangle C F A\left(2 \times 10^{6} \mathrm{CFU} \mathrm{mL}-1\right)$, a mutant of Pst DC3000 that does not produce coronatine or a functional type III secretion system, over the course of 28 days after infection of Arabidopsis accession Col-0. Photographs of representative infected plants are shown beneath the graph. (B) Bacterial population density numbers of Pst DC3000 $\left(2 \times 10^{6}\right.$ CFU mL ${ }^{-1}$ ) over the course of 28 days after infection of Arabidopsis accession Bu-22. Bu-22 carries RPS7, a gene that recognizes the effector AvrPto, and triggers effector-triggered immunity. (C) Bacterial population density numbers of endophytic microbiota strain Pandoraea sp. Col-0-28 (106 CFU mL $\left.{ }^{-1}\right)$ over the course of 20 days after infection of Col-0 plants. (D) Bacterial population density numbers of non-pathogenic $P$. fluorescens $(P f)$ 0-1 (2 $\times 10^{5} \mathrm{CFU} \mathrm{mL} \mathrm{m}^{-1}$ ), a bacterium isolated from soil, over the course of 20 days after infection of Col-0 plants. There is a decrease in population density observed over time.

Individual biological repetitions for each treatment are shown as open circles. Error bars indicate the standard error of the mean. When appropriate, different letters indicate differences in means, as judged by a Tukey HSD test $(p<0.05)$. dpi indicates days postinoculation. 
Figure 2

A

Pst $\triangle$ hrcC $\triangle$ CFA

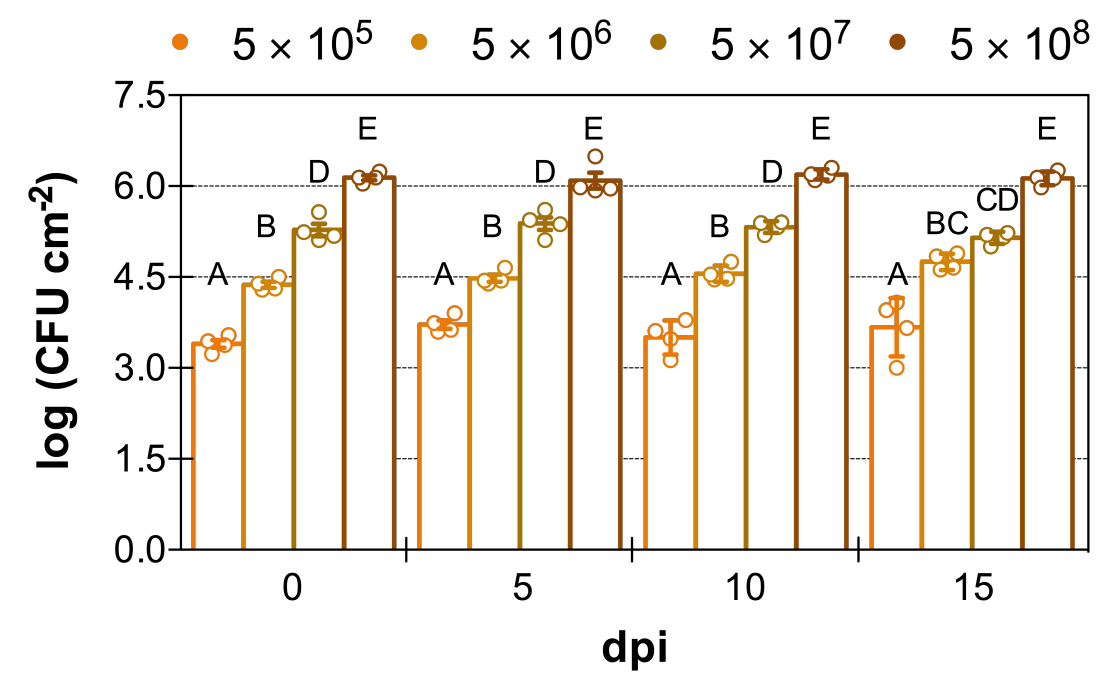

B

Pst $\triangle h r c C \triangle C F A$

- WT $\quad b b c$

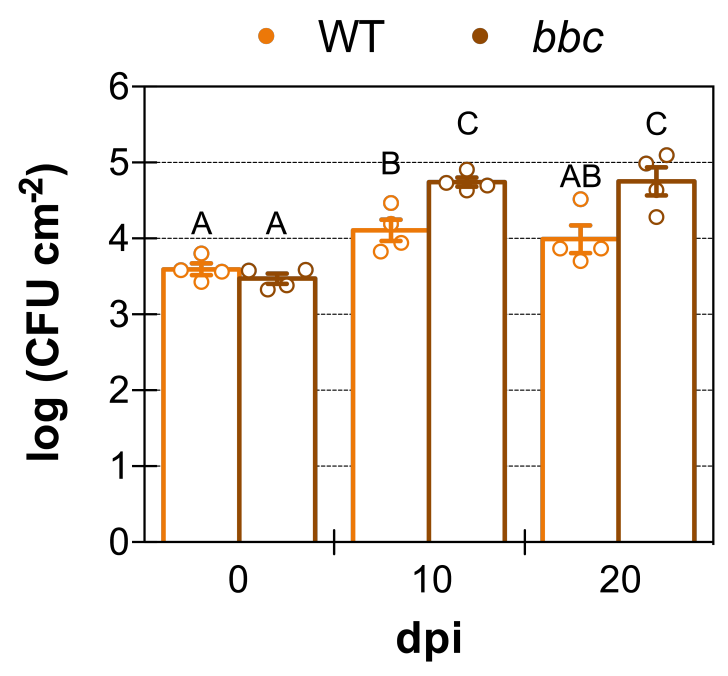

Pf 0-1

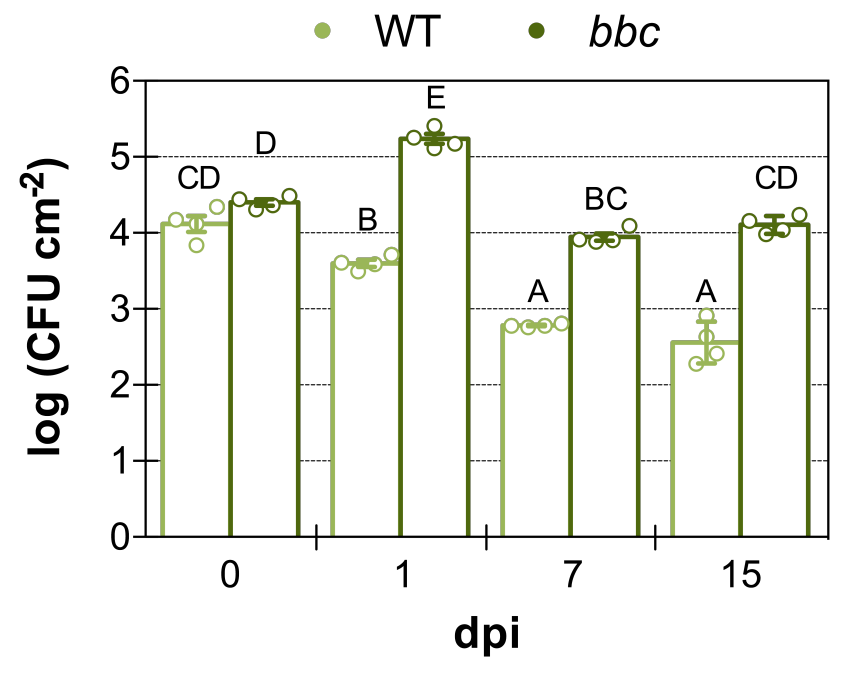

C

Pst DC3000 inoculi recovered from:

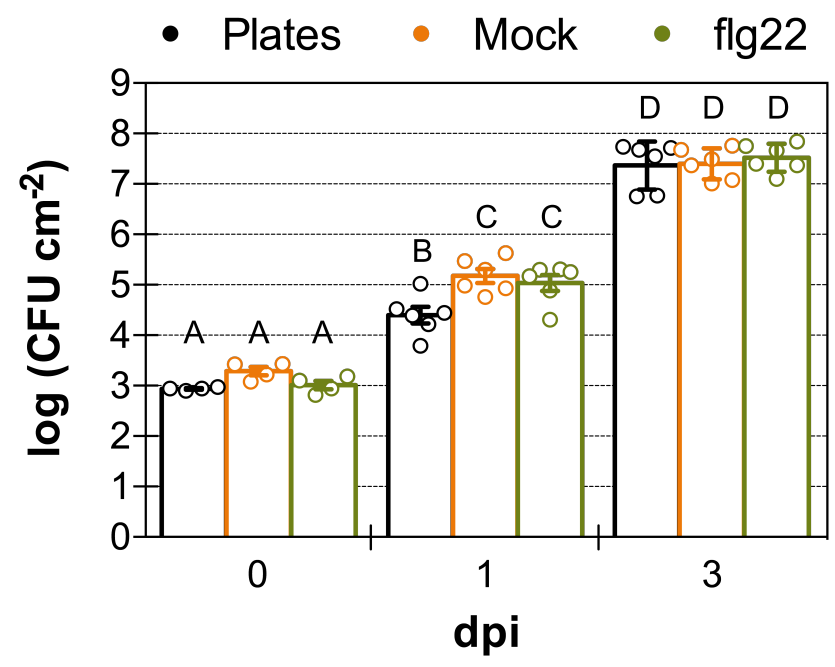


Figure 2. Bacterial population stasis is a reversible physiological state independent of bacterial density or PAMP-triggered immunity (A) Bacterial population density in Col-0 plants after infiltration with different inoculum concentrations of Pst $\triangle h r c C \triangle C F A$ (in CFU mL-1). Bacterial population density remains static for over two weeks, irrespective of the starting bacterial inoculum concentration. (B) Compromising PTI is not sufficient to have sustained growth of non-pathogens. Bacterial population density in Col-0 and PTI-compromised triple mutant bak1 bkk1 cerk1 (bbc) in Pst $\triangle$ hrcC $\triangle C F A$ and P. fluorescens $0-1\left(2 \times 10^{6} \mathrm{CFU} \mathrm{mL}^{-1}\right)$ over the course of up to 20 days. (C) Bacteria recovered from tissue experiencing flagellininduced population stasis are as capable as causing disease as those from naïve plants.

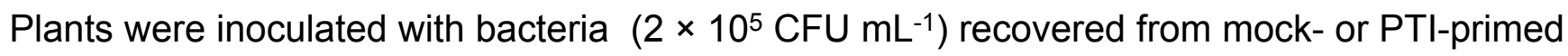
plants (with DMSO or flg22, an elicitor from bacterial flagellin that induces PTI). As an inoculum control, bacteria grown in vitro on LM plates were used.

Individual biological repetitions for each treatment are shown as open circles. Error bars indicate the standard error of the mean. When appropriate, different letters indicate differences in means, as judged by a Tukey HSD test $(p<0.05)$. dpi indicates days postinoculation. 
Figure 3

A

Logarithmic growth

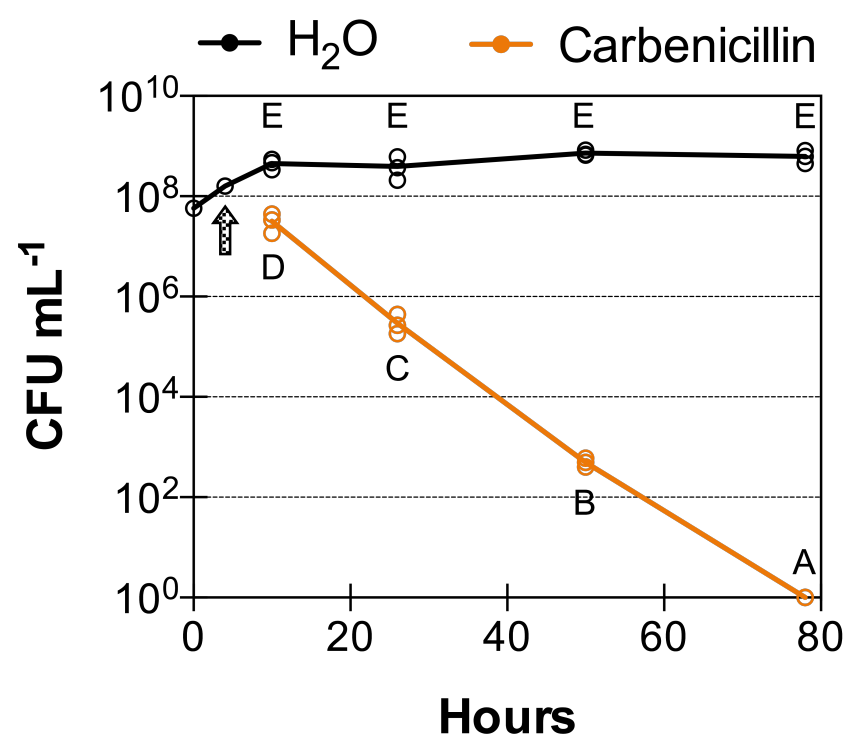

Stationary growth

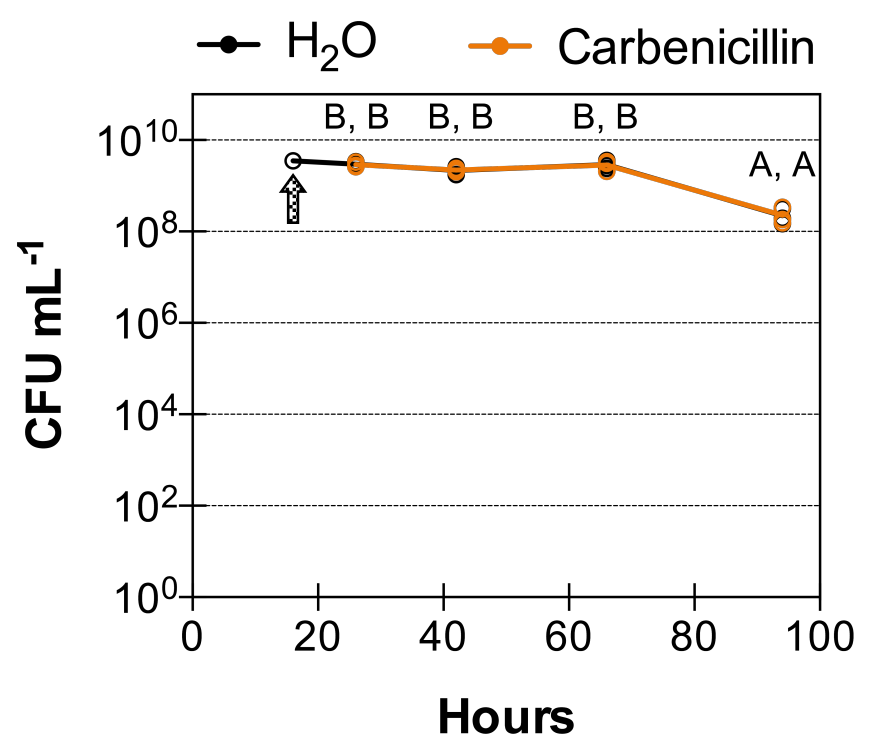

B

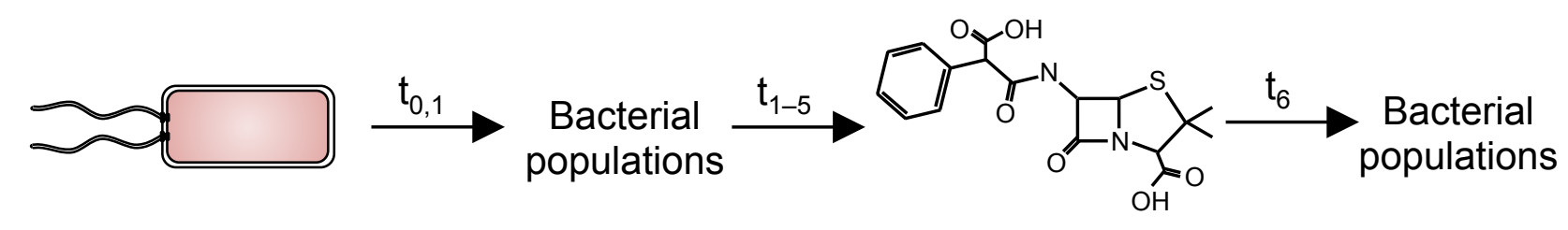

Pst $\triangle \mathrm{hrcC} \triangle \mathrm{CFA}$

$\circ-\mathrm{H}_{2} \mathrm{O} \cdot$ Carbenicillin

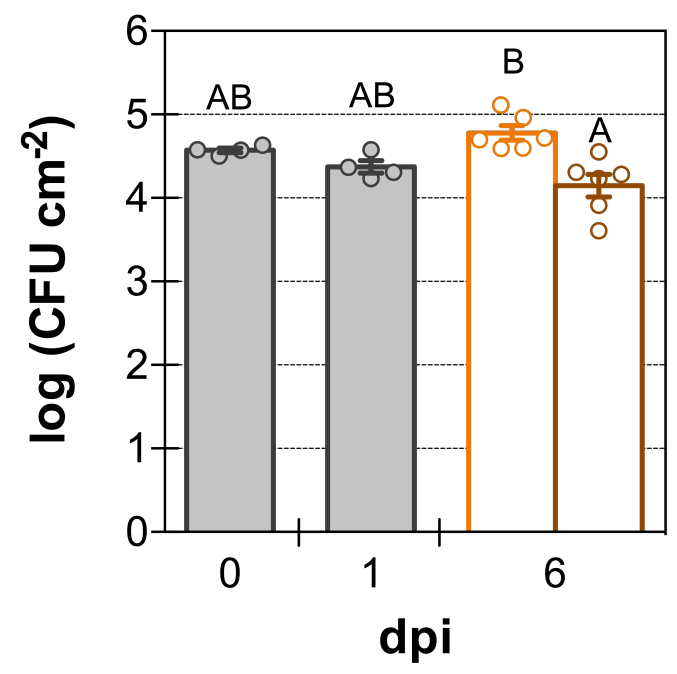

$\beta$-lactam antibiotic

Pandoraea

$\circ-\mathrm{H}_{2} \mathrm{O}$ - Cefotaxime

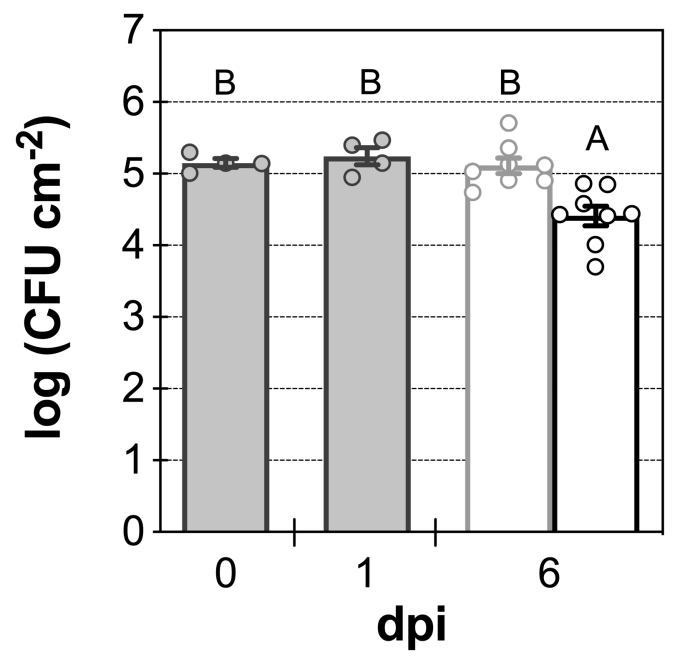


Figure 3. Apparent bacterial population stasis is caused by an equilibrium between individual cell death and multiplication. (A) Stationary culture density is unaffected by the antibiotic carbenicillin, which only targets actively dividing bacteria. In vitro growth (in LM media) of $P$. syringae pv. tomato (Pst) $\triangle$ hrcC $\triangle C F A$ cultures in logarithmic or stationary phase after the addition of $400 \mu \mathrm{g} \mathrm{mL}^{-1}$ of carbenicillin or $\mathrm{H}_{2} \mathrm{O}$ control. The arrow indicates the time at which $\mathrm{H}_{2} \mathrm{O}$ or the antibiotic was added to the culture. The $y$-axis is a logarithmic scale. (B) In planta bacterial population density of Pst $\triangle$ hrcC $\triangle C F A\left(10^{7} \mathrm{CFU} \mathrm{mL} \mathrm{L}^{-1}\right)$ or Pandoraea sp. Col-0-28 (5 $\left.\times 10^{7} \mathrm{CFU} \mathrm{mL}{ }^{-1}\right)$ in Col-0 plants after the addition of $400 \mu \mathrm{g} \mathrm{mL}^{-1}$ of carbenicillin or cefotaxime, $\beta$-lactam antibiotics that target cell wall biosynthesis and only kill dividing bacteria. Over $70 \%$ of the population is killed over the course of 5 days.

Individual biological repetitions for each treatment are shown as open circles. Error bars indicate the standard error of the mean. Different letters indicate differences in means, as judged by a Tukey HSD test $(p<0.05)$. dpi indicates days post-inoculation. $t_{x}$ indicates the number of days post inoculation. 
Figure 4

A

\section{FP-tagged bacteria}
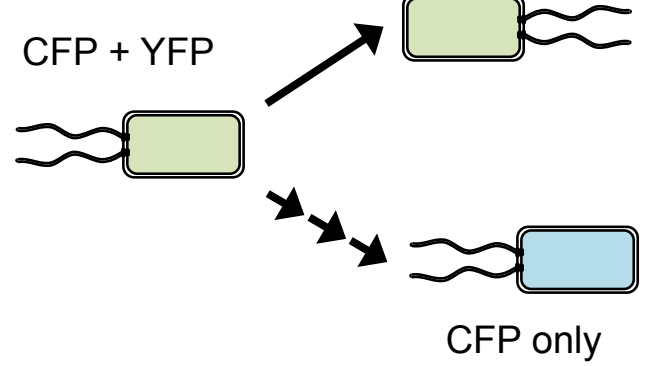

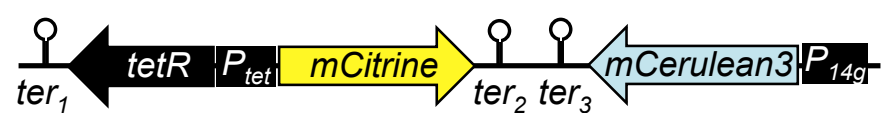

B $\quad \Delta h r c C \triangle C F A P_{\text {tet }}-m$ Citrine_ $P_{14 g}-m$ Cerulean3
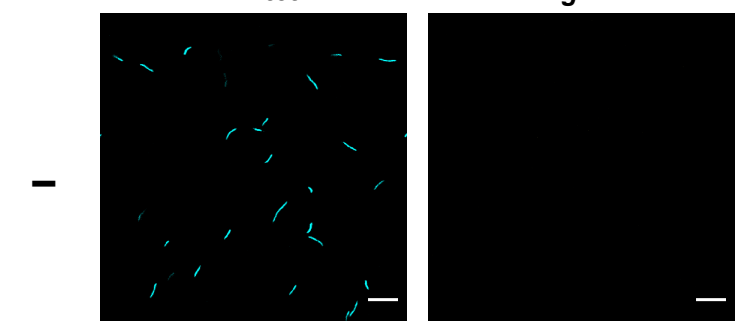

aTc

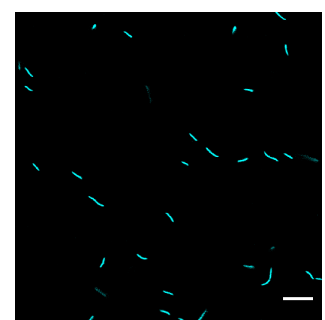

CFP channel

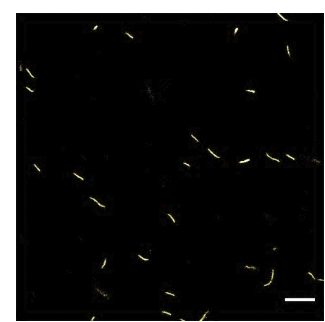

YFP channel

C DC3000 $P_{\text {tet }}-m$ Citrine_ $P_{14 g}-m$ Cerulean3 + aTc
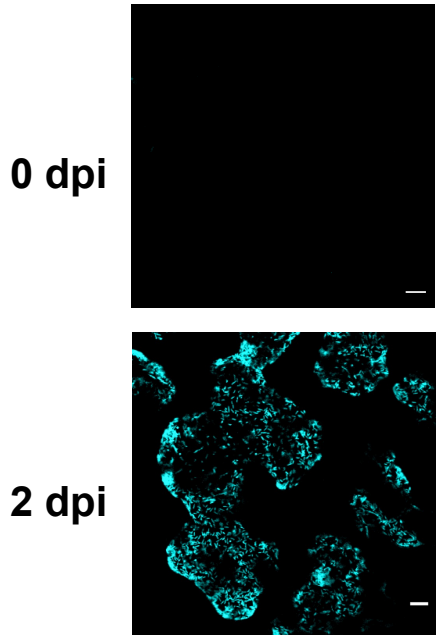

CFP channel
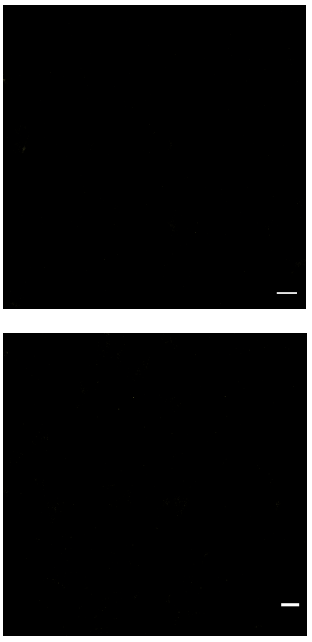

YFP channel
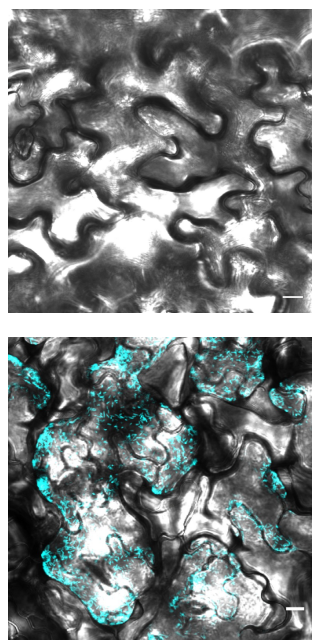

Composite

D $\quad \triangle$ hrcC $\triangle$ CFA $P_{\text {tet }}-m$ Citrine_P $P_{14 g}-m$ Cerulean3 + aTc
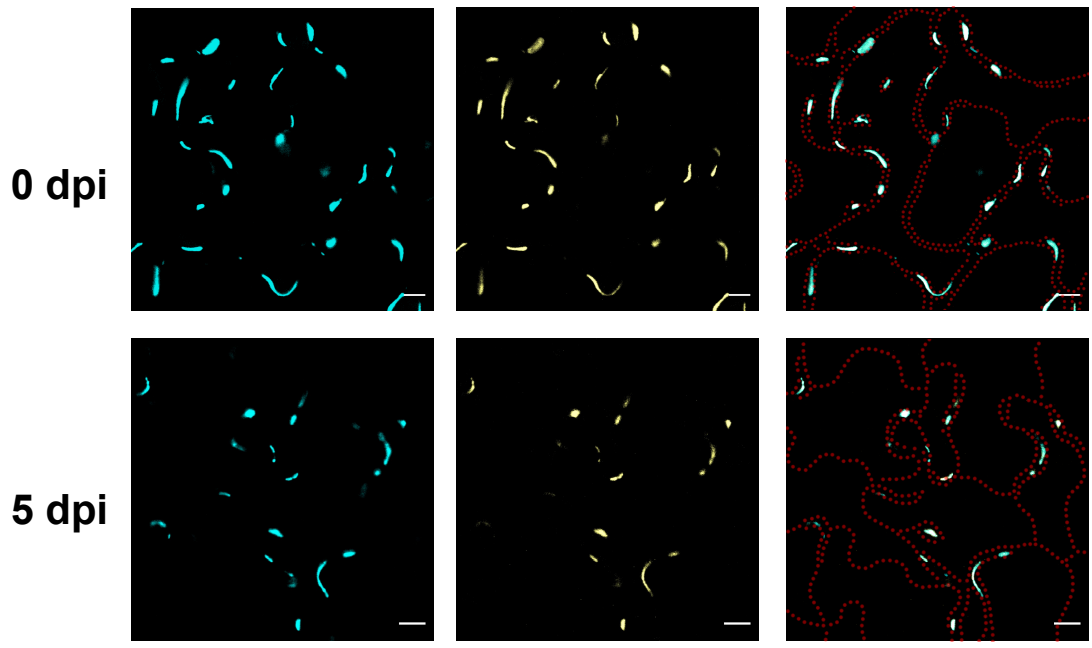

CFP channel

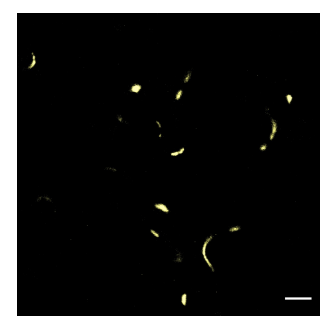

YFP channel

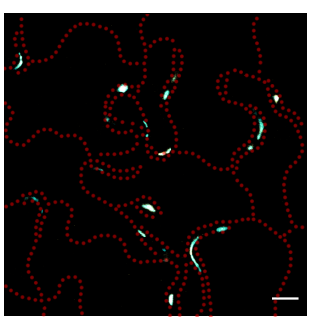

Composite

E

$\triangle h r c C \triangle C F A$

$P_{\text {tet }}-$ Citrine_$P_{14 g}$ $-m$ Cerulean $3+$ aTc 5 dpi

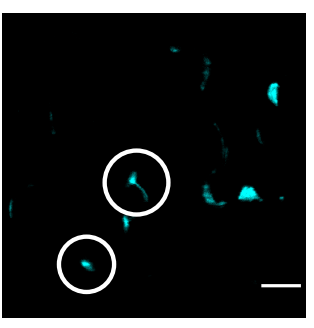

CFP channel

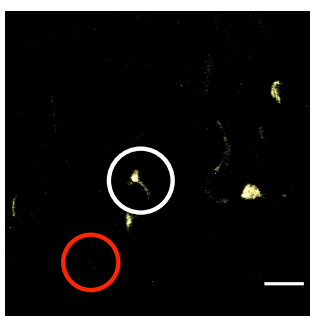

YFP channel

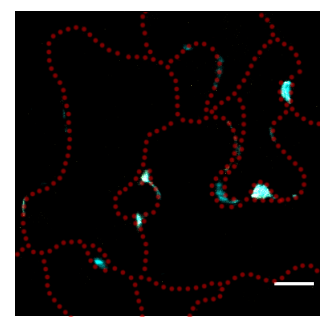

Composite 
Figure 4. Visualization of in planta population stasis of bacterial endophytes. (A) Construct integrated into the $P$. syringae pv. tomato $(P s t)$ genome. The tetracycline promoter $\left(P_{\text {tet }}\right)$ controls the bidirectional expression of the tetR transcriptional regulator and of fluorescent protein mCitrine. The strong constitutive $P_{14 g}$ promoter controls the expression of fluorescent protein mCerulean3. There are 3 different transcriptional terminators (ter) in the construct. Above the construct is a schematic representation of the dilution of fluorescent protein (FP) signal when a bacterium divides. mCitrine signal is conditionally expressed only in the presence of anhydrotetracycline (aTc); if the inducer is absent and bacteria multiply (represented by multiple consecutive arrows), only the constitutive mCerulean3 signal would be observed. (B) Confocal images of Pst $\triangle$ hrcC $\triangle C F A$ carrying the fluorescent division reporter $P_{\text {tet }}-m$ Citrine_ $P_{14 g}$ - $m$ Cerulean3 after in vitro growth with or without the addition of 67 $\mathrm{ng} \mu \mathrm{L}^{-1}$ of aTc to induce mCitrine expression. (C) Confocal images of virulent Pst DC3000 carrying the fluorescent division reporter $\left(5 \times 10^{7} \mathrm{CFU} \mathrm{mL}^{-1}\right.$; inoculum grown with $80 \mathrm{ng} \mathrm{mL}^{-1}$ aTc) 2 hours $(0 \mathrm{dpi})$ and 2 days after inoculation of Col-0 plants. Fluorescent signal from mCerulean 3 is only observed at the high population densities achieved at $2 \mathrm{dpi}$, while no inducible mCitrine signal is observed in the samples. (D) Confocal images of non-pathogenic Pst $\triangle h r c C \triangle C F A$ carrying the fluorescent division reporter $\left(10^{9} \mathrm{CFU} \mathrm{mL}^{-1}\right.$; inoculum grown with $80 \mathrm{ng} \mathrm{mL}^{-1} \mathrm{aTc}$ ) 3 hours ( $0 \mathrm{dpi}$ ) and 5 days after inoculation of Col-0 plants. Signal of both FPs mostly overlap. (E) Close-up of two bacterial aggregates, one with and one without mCitrine signal, indicating a static sub-population (white circle overlaid on the YFP-channel image) and one that arose from in planta bacterial multiplication (red circle), respectively. Cyan represents signal from $m$ Cerulean3. Yellow represents signal from $m$ Citrine. Composite image of both FPs is also shown; in Figure 4C, the transmitted light image is overlaid, while in Figures $4 \mathrm{D}$ and $4 \mathrm{E}$, the cell outlines are overlaid as red dotted lines. White bars represent 10 $\mu \mathrm{m}$. dpi indicates days post-inoculation. 
bioRxiv preprint doi: https://doi.org/10.1101/2021.05.10.443510; this version posted May 10, 2021. The copyright holder for this preprint (which was not certified by peer review) is the author/funder, who has granted bioRxiv a license to display the preprint in perpetuity. It is made available under aCC-BY-NC-ND 4.0 International license.

\section{Figure 5}

A

$$
\log _{2} \mathrm{FC}\left(\mathrm{t}_{\mathrm{x}} / \mathrm{KB}\right) \quad \Delta \boldsymbol{h r c C} \Delta \boldsymbol{C F A}
$$

$-10.9 \quad 9.6$
Virulence
Hexose
Catabolism and
ATP biosynthesis
Alginate

Alginate

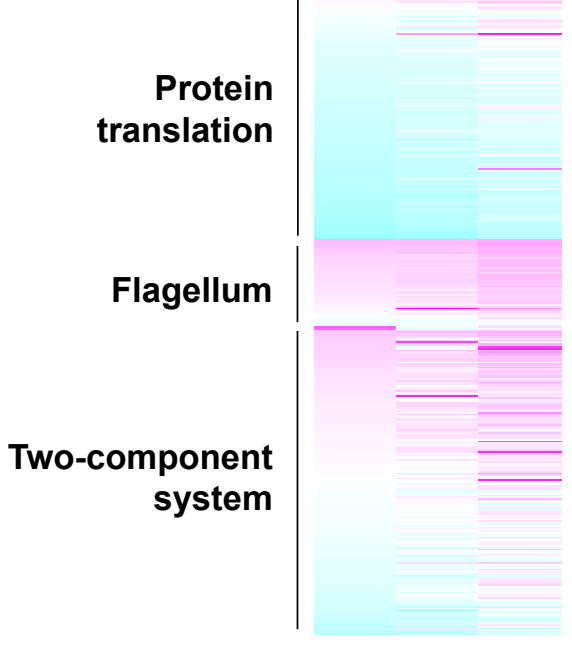

B

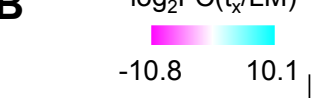

$\log _{2} \mathrm{FC}\left(\mathrm{t}_{\mathrm{x}} / \mathrm{LM}\right)$

\begin{tabular}{ccc} 
Achromobacter & \multicolumn{4}{c}{$t_{6}$} & $t_{24}$ & $t_{168}$ \\
\hline
\end{tabular}

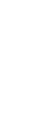

biosynthesis Sulfate transport Protein folding

D Inoculum vs. $t_{168}$

Amino acid catabolism Locomotion and flagellum Response to chemical stimulus Transcriptional regulation Allantoin metabolism Glutathione metabolism Siderophore transport Sulfur amino acid biosynthesis tRNA aminoacylation ATP biosynthesis Protein translation Response to oxidative stress Ribosome biogenesis Transport across membranes Tricarboxylic acid cycle Virulence

Alginate biosynthesis Amino acid biosynthesis Bacterioferritin Carbohydrate metabolism Entner-Doudoroff and PPP Proteolysis Nucleotide metabolism Urea metabolism
E

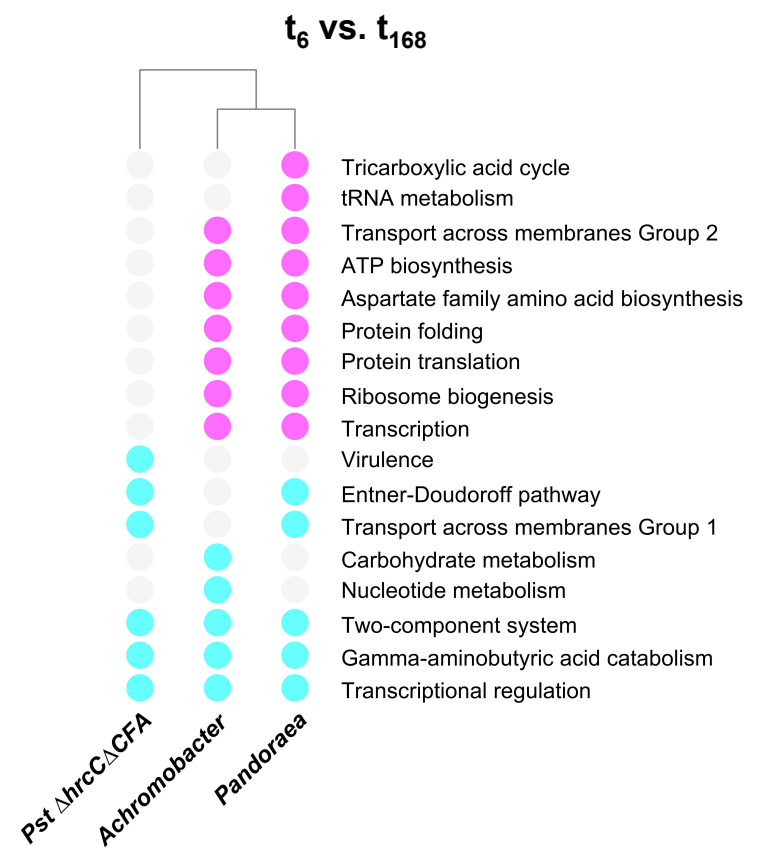


Figure 5. Transcriptome analysis of three phyllosphere-inhabiting bacteria. (A) Longterm in planta transcriptome heatmap of gene expression of select categories in nonpathogenic $P$. syringae pv. tomato (Pst) $\triangle$ hrcC $\triangle C F A$. (B) Long-term in planta transcriptome heatmap of select categories of bacterial microbiota member Achromobacter xylosoxidans Col-0-50. Only endophytic bacteria were used for the analysis. (C) Long-term in planta transcriptome heatmap of select categories of bacterial microbiota member Pandoraea sp. Col-0-28. (D) Up- or down-regulation of expression of enriched biological processes of differentially expressed groups of orthologous genes shared between Pst $\triangle$ hrcC $\triangle C F A, A$. xylosoxidans, and Pandoraea sp., shared between two strains, or unique to each strain, when comparing the inoculum to 168 hours post-inoculation or (E) 6 to 168 hours post-inoculation into Col-0 plants.

For the transcriptome heatmaps, gene expression values of select categories were graphed in ascending order of their $\log _{2}$ fold change (FC) of the ratio between $6\left(t_{6}\right), 24\left(t_{24}\right)$ or 168 $\left(t_{168}\right)$ hpi and the expression in the inoculum (KB or LM). FC was color coded for repression (magenta), no change (white), and induction (cyan), with the same color scheme used for upregulation or down-regulation of biological processes. PPP refers to the Pentose phosphate pathway, while KB and LM refer to the bacterial inoculi, which were grown in King's B medium or modified LB, respectively. 
bioRxiv preprint doi: https://doi.org/10.1101/2021.05.10.443510; this version posted May 10, 2021. The copyright holder for this preprint (which was not certified by peer review) is the author/funder, who has granted bioRxiv a license to display the preprint in perpetuity. It is made available under aCC-BY-NC-ND 4.0 International license.

\section{Figure 6}

A

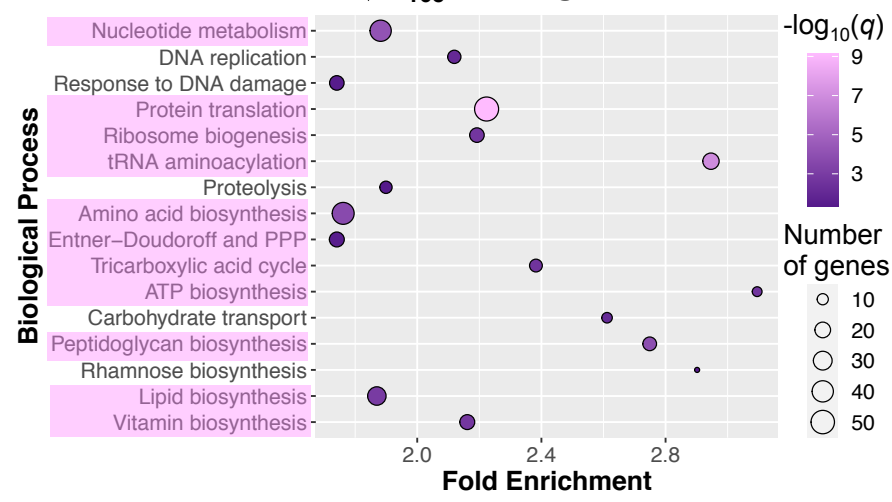

$\downarrow$ Stationary vs. Logarithmic

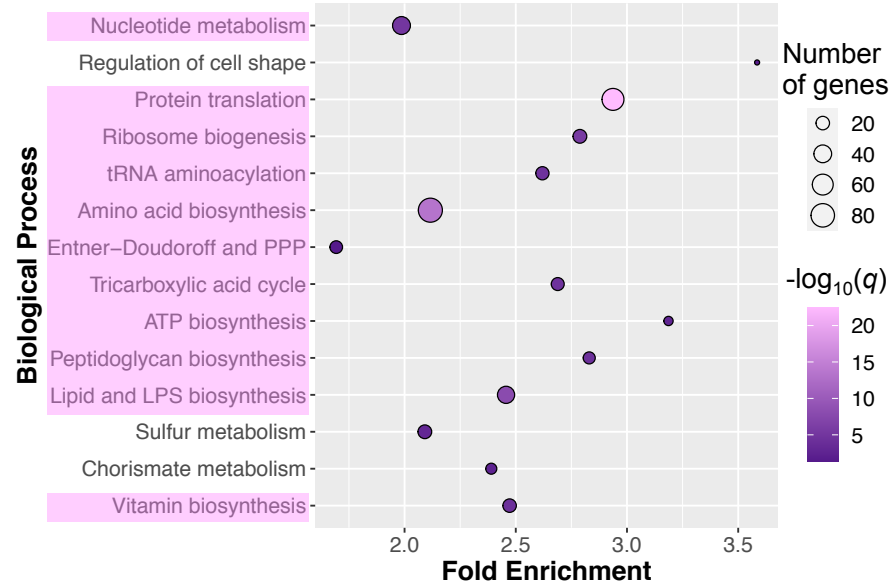

B
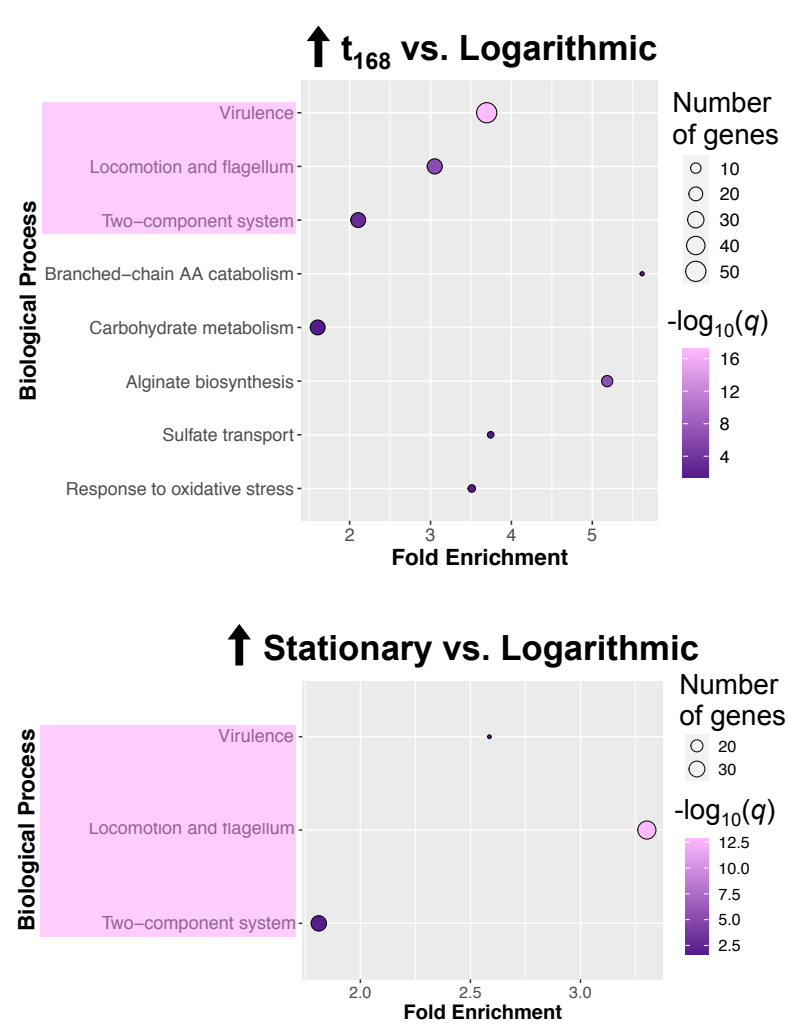
Figure 6. Static phyllosphere-inhabiting bacterial populations show similar transcriptional responses to populations in stationary phase. (A) Bubble graph of enriched biological processes in differentially expressed genes (DEGs) down-regulated at 168 hours post-inoculation $\left(\mathrm{t}_{168}\right)$ or in in vitro stationary-phase populations, when compared to in vitro logarithmic-phase populations. Processes found in both comparisons are highlighted in pink. (B) Bubble graph of the same comparisons as in D, but using the enriched biological processes from up-regulated DEGs.

For the bubble graphs, the fold-enrichment, number of significant DEGs, and the $\log _{10}$ of the adjusted $p$-value $(q)$ is shown for each biological process. PPP refers to the Pentose phosphate pathway. 


\section{Figure 7}

A

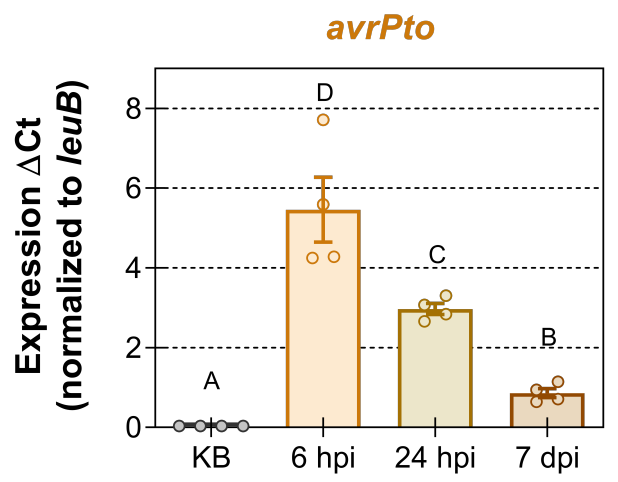

Pst $\triangle$ hrcC $\triangle$ CFA

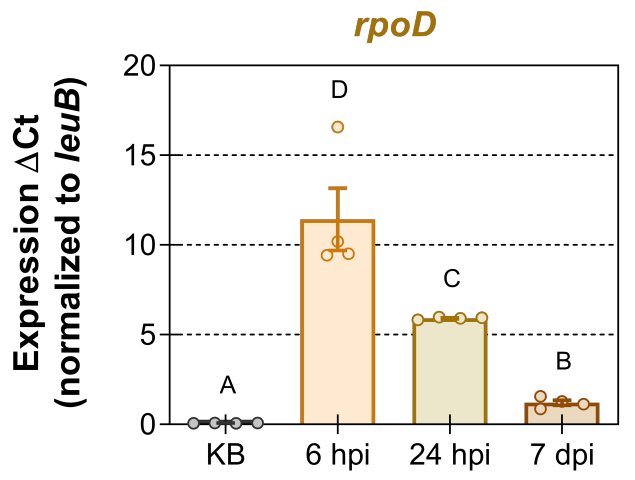

Pst $\triangle$ hrc $C_{\triangle} C F A$

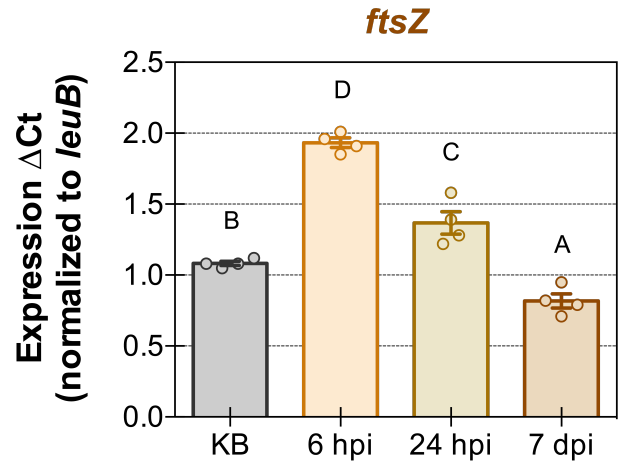

B

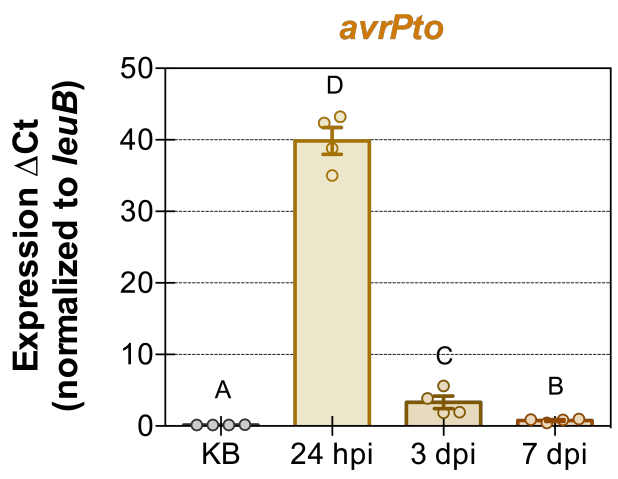

Pst DC3000 (RPS7)

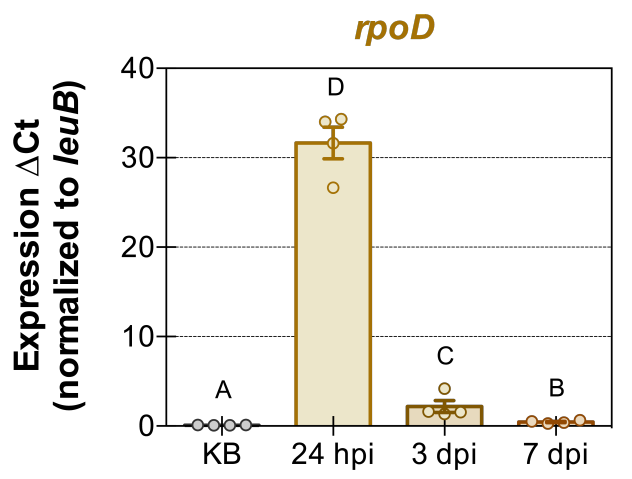

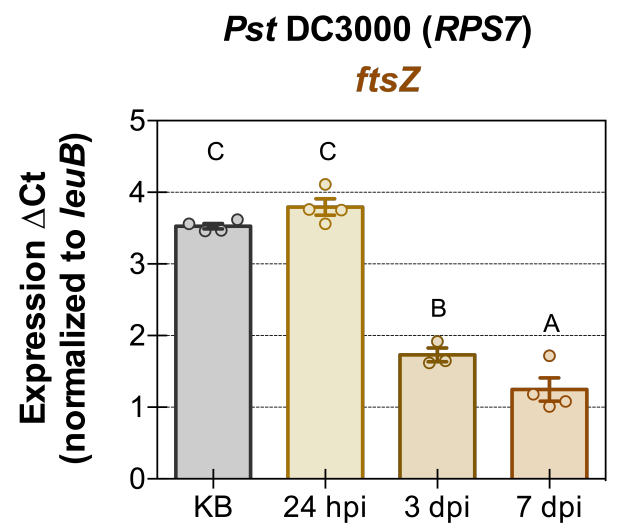


Figure 7. Bacteria experiencing effector-triggered immunity have a transcriptional response that mimics non-pathogenic endophytic bacteria. (A) In planta gene expression of a type III effector (avrPto), the housekeeping RNA polymerase sigma factor $(r p o D)$, and a gene involved in bacterial cell division (ftsZ) after inoculation with Pst $\triangle h r c C \triangle C F A$ into Col-0 plants. (B) In planta gene expression of the same genes as in 4D after inoculation with Pst DC3000 into Bu-22 plants, an interaction that triggers effector-triggered immunity.

For quantitative reverse-transcriptase $\mathrm{PCR}$, gene expression was evaluated using leuB as the reference gene and the $\Delta \mathrm{Ct}$ method. Error bars indicate the standard error of the mean. Different letters indicate differences in means, as judged by a Tukey HSD test $(p<0.05)$, which was performed between the $\Delta$ Ct values. hpi indicates hours post-inoculation, dpi indicates days post-inoculation, and KB refers to the bacterial inoculum, which was grown in King's B medium. 